\title{
ARQUITECTURA Y PATRÓN DE ASENTAMIENTO EN EL INTERMEDIO TARDÍO. INVESTIGACIONES EN LA FRONTERA ESTE, NORTE Y NOROESTE DE LA COMUNIDAD DE CHACCCHAHUA, DISTRITO HUACCANA - APURÍMAC ${ }^{1}$
}

\author{
DANIEL AlLENDE JOAQuíN \\ UnIVERSIDAD NACIONAL DE SAN CRISTÓBAL DE HUAMANGA \\ dan51997@hotmail.com
}

\section{RESUMEN}

Se muestra los resultados de las investigaciones arqueológicas realizados en la frontera Este, Norte y Noroeste de la comunidad de Chaccchahua, distrito de Huaccana, Chincheros - Apurímac. Es, entre otras cosas, nuestro objetivo, mostrar una forma alternativa de ver los patrones de asentamiento durante el Intermedio Tardío (1000 a.C. - 1400 a.C.), tomando en cuenta, la ubicación, la arquitectura, la movilidad espacial, su organización y en especial, los recursos medio - ambientales presentes en esta área. Además, dar una puerta de entrada a futuras discusiones y comparaciones con otros sitios presentes en áreas colindantes, para encontrar similitudes y diferencias. Partimos con la premisa: la ocupación prehispánica en la frontera Este, Norte y Noroeste de la comunidad de Chaccchahua está marcado por poblados fortificados, con el patrón de asentamiento muy particular, una movilidad espacial muy marcado y el control territorial de más de 3 regiones naturales (yunga fluvial, quechua, suni y puna). Se tiene registrado más de una decena de sitios ubicados en las partes altas o crestas de los cerros, las partes intermedias y partes más bajas, con una continua ocupación desde el Formativo hasta el advenimiento incaico, con una mayor ocupación del intermedio tardío.

Palabras Clave: Huaccana, Chaccchahua, Grupos Étnicos Interdependientes, Intermedio Tardío, Arquitectura, Patrón de Asentamiento.

1. Ponencia presenta al XXII CONEAR “Mario Benavides Calle”, realizado del 22 al 27 de setiembre del 2014. 


\section{ABSTRACT}

The results of archaeological research conducted in the East, North and Northwest border Chaccchahua community, district Huaccana, Chincheros, Apurimac shown. It is, among other things, our goal, to show an alternative way to see the patterns of settlement during the Late Intermediate (1000 BC - $1400 \mathrm{BC}$ ), taking into account the location, architecture, spatial mobility, organization and especially the average resources - environmental present in this area. Moreover, giving a gateway to future discussions and comparisons with other sites present in neighboring areas, to find similarities and differences. We start with the premise: the prehistoric occupation in the East, North and Northwest Community Chaccchahua border is marked by fortified settlements, with the pattern of very particular settlement, a very strong spatial mobility and territorial control over 3 natural regions (river yunga, Quechua, suni and puna). It has been more than a dozen sites located in the upper parts or ridges of the hills, the intermediate parts and lower parts, with a continuous occupation from the training to the Inca coming with higher occupancy late intermission.

Keywords: Huaccana, Chaccchahua, Interdependent Ethnic Groups, Late Intermediate, Architecture, Settlement Pattern.

\section{INTRODUCCIÓN}

La información presentada corresponde a una serie de investigaciones arqueológicas, en el ámbito de la prospección y análisis de evidencias, en la comunidad de Chaccchahua, distrito de Huaccana, provincia chincheros departamento de Apurímac.

La carencia de investigaciones arqueológicas en la comunidad de Chaccchahua, distrito de Huaccana, provincia Chincheros departamento de Apurímac y el masivo proceso de destrucción sistemático que sufren los sitios por diferentes factores, como la ampliación de la frontera agrícola, el intensivo proceso de pastoreo de ganados vacunos, equinos y ovinos, y los factores medioambientales, generan la pérdida de valiosa información, los cuales nos motivó a realizar el registro de los sitios arqueológicos presentes en esta área.

En la frontera Este, Norte y Noreste de la comunidad de Chacchahua se constató la existencia de una decena de sitios arqueológicos que van desde los 2600 m.s.n.m. hasta los 3800 m.s.n.m. Estos corresponden a asentamientos residenciales con recintos habitacionales de plantas circulares y cuadrangulares, andenerías, cistas, murallas, muros, zanjas, calles principales y secundarias, chullpas, ushnu y abrigos rocosos, los cuales nos inducen a la existencia de sociedades con una organización arquitectónica y administrativa muy compleja y muy bien organizada; a la vez, dedicada a diversas actividades.

\section{Categorías y Conceptos}

Los trabajos de campo, en especial, la prospección arqueológica, consiste en la búsqueda sistemática de los restos arqueológicos y punto de partida de la investigación (Lumbreras 1974: 37), que incluye un registro de los accidentes topográficos, direcciones, vías de acceso, vegetación, hidrografía y aspectos ecológicos (Ravines 1989: 12), que involucra una serie de actividades previas a la salida del campo, como: la consulta de fuentes documentales y la evidencia toponímica (Renfrew y Bahn 1998: 67) el establecimiento de una base de trabajo, el reconocimiento preliminar del sitio, el levantamiento topográfico y el dibujo técnico (Litvak 2000: 68), la recolección de material diagnóstico que se encuen- 
tra en la superficie, el análisis de los materiales y por último, la elaboración de un informe con los resultados de la investigación.

En tal sentido, los trabajos de campo en el área de estudio consistió en el registro de sitios usando un mapa del IGN (Carta Nacional, escala: 1/100,000: 27 - O, San Miguel) e internet en Google Earth; además, se usó un GPS, para fines de coordenadas del sistema UTM y la altitud. Se procedió mediante la técnica del "transecto", y en "zig-zag" para ubicar los sitios arqueológicos, como: sitios sin arquitectura (concentraciones de material lítico o cerámico), asentamientos con arquitectura (poblados), andenerías, sistemas hidráulicos, caminos, cuevas o abrigos rocosos, los mismos que fueron sectorizados teniendo en cuenta las evidencias y rasgos culturales comunes o se diferencian entre ellas en una misma área.

Por otro lado, las evidencias arquitectónicas, en su análisis, descripción y clasificación, involucra la aplicación de métodos y técnicas de una disciplina arqueológica en particular, el patrón de asentamiento, consiste en analizar el modo en el cual el hombre se desarrolla en el medio ambiente en que vive, tales como sus viviendas, su arreglo, o distribución, la naturaleza y disposición de otros edificios para lograr varias finalidades, describir una serie de sitios con referencia a su posición cronológica y geográfica, reconstruir el proceso cultural con relación a su secuencia (Willey 1953:1) y el entendimiento de la organización territorial de un asentamiento (Morales 2010: 8).

\section{Estudios Previos}

Las investigaciones arqueológicas correspondientes en el distrito de Huaccana, y en especial en la frontera Este, Norte y Noroeste de la comunidad de Chaccchahua, no es muy extensa, sin embargo tenemos a Allende et.al. 2014, González Carré et. al. (1988), Valer (2006), Vivanco (2011 a 2011b). Para el valle del río Pampas, Espinoza (2003). Para el micro-cuenca del río Chincheros, Salcedo (2009).

El área de Andahuaylas y el valle del Chumbao, cuenta con varias investigaciones arqueológicas, que registran varios sitios. Grossman (1972 y 1983), Amorin y Alarcón (1999), Pérez et al. (2003), Bauer et al (2002, 2004, 2010a, 2010b y 2010c), Kurin y Gómez (2010); Gómez (2007), Quispe (2001) y otros.

Para el caso de Chungui y la confluencia del Apurímac, las investigaciones arqueológicas es muy significativa por las evidencias encontradas, Añanca et. al. (2009 y 2013), Vivanco (2011c) y Saintenoy (2008).

\section{Asentamientos en la Frontera Este, Norte y Noroeste de la Comunidad DE CHACCCHAHUA}

En la frontera Este, Norte y Noroeste de la comunidad de Chaccchahua, se registró 10 sitios arqueológicos (fig. 1 y 2), mediante la aplicación de una serie de actividades metodológicas, que involucra, el trabajo de campo y gabinete.

SITIO 01: CÓNDOR RUMI (CR01); ubicado al Noroeste de la comunidad de Chaccchahua. Entre las coordenadas UTM: 8525184N y 0631172E a 2871 m.s.n.m. compuesto de: Andenerías (fig. 3) separadas por muros de doble hilera, distribuidos de Sur a Norte, construidos con mampostería ordinaria, sin argamasa, ni mortero; de los cuales el $80 \%$ está en mal estado de conservación, tienen de 1.20 a 2 $\mathrm{m}$ de altura, de 30 a $40 \mathrm{~m}$ de largo y de 2.60 a $3 \mathrm{~m}$ la distancia de andén a otro. Recintos circulares y cuadrangulares (fig. 4), adosados a los muros y sobre los andenes, hechos con mampostería ordinaria, 
con acceso orientado al Norte y Noreste, sin argamasa, con relleno de tierra, piedras pequeñas y fragmentos de cerámica; asociado a batanes y manos de molienda en el interior. Tienen un diámetro que varía de 2.50 a $3 \mathrm{~m}$, con 0.30 a $0.60 \mathrm{~cm}$ de ancho del muro, 1 a $1.10 \mathrm{~m}$ de altura y 0.50 a $0.70 \mathrm{~cm}$ el acceso.

Camino: recorre de Sur a Noreste, delimitado por muros de doble hilera, presenta graderías compuestas de 2 a 3 piedras planas y rectangulares, tiene de $0.90 \mathrm{~m}$ a $3.70 \mathrm{~m}$ de ancho, con muro de $0.80 \mathrm{~m}$ a $1 \mathrm{~m}$ de altura y $80 \mathrm{~cm}$ de ancho (fig. 5). Chullpa (fig. 6): situado al Sureste, en el interior y paramento

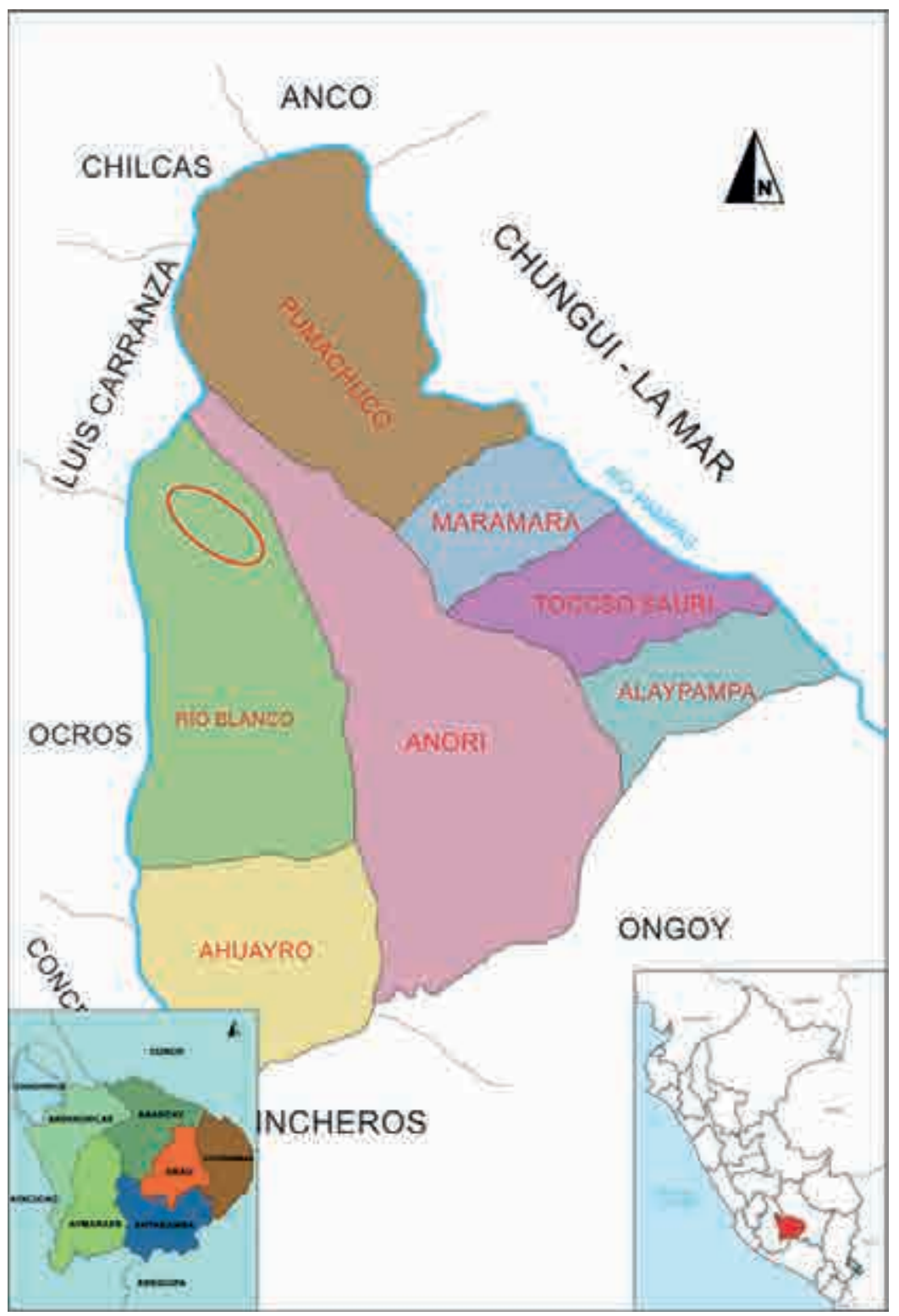

Fig. 1: distrito de Huaccana y la ubicación del área de estudio (círculos rojo) con relación al departamento de Apurímac. 


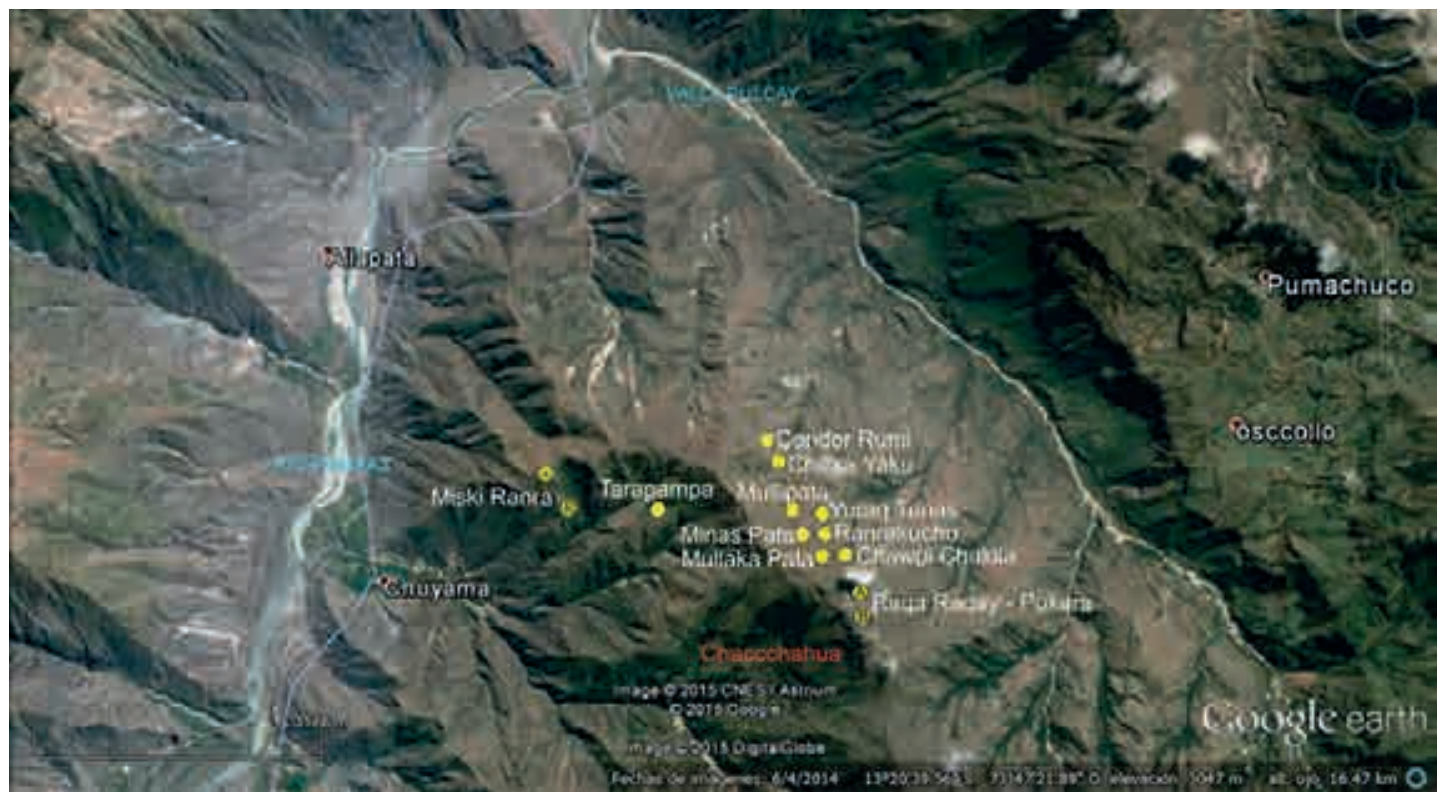

Fig. 2: vista satelital de los sitios registrados en la frontera Este, Norte y Noroeste de la comunidad de Chaccchahua.

de un andén, sobre un recinto circular. El interior tiene cimiento circular y el techo abovedado, con acceso de una sola piedra alargada en el dintel, sobre dos piedras alargadas, tiene 1.50 a $1.60 \mathrm{~m}$ de diámetro y de 1 a $1.10 \mathrm{~m}$ de altura. Abrigos rocosos: situados al Oeste, compuesta de rocas de grandes dimensiones, dos de las cuales están asociadas a restos óseos y fragmentos de cerámica.

SITIO 02: CHILLKA YAKU (CHY02); ubicado a $1 \mathrm{~km}$ al Sur del primer sitio (Cóndor Rumi), al Noroeste de la comunidad de Chaccchahua. Está dividido en 3 sectores: A, B y C. El sector A, ubicado entre las coordenadas UTM: 8524684N y 631255E, a 3016 m.s.n.m. compuesto de gran cantidad de andenerías (fig. 7) hechos con mampostería ordinaria, distribuidos por toda una suave pendiente. Tienen de 1 a $1.70 \mathrm{~m}$ de altura, de 10 a $12.70 \mathrm{~m}$ de largo y de 2 a $10 \mathrm{~m}$ distancia de anden a otro. El
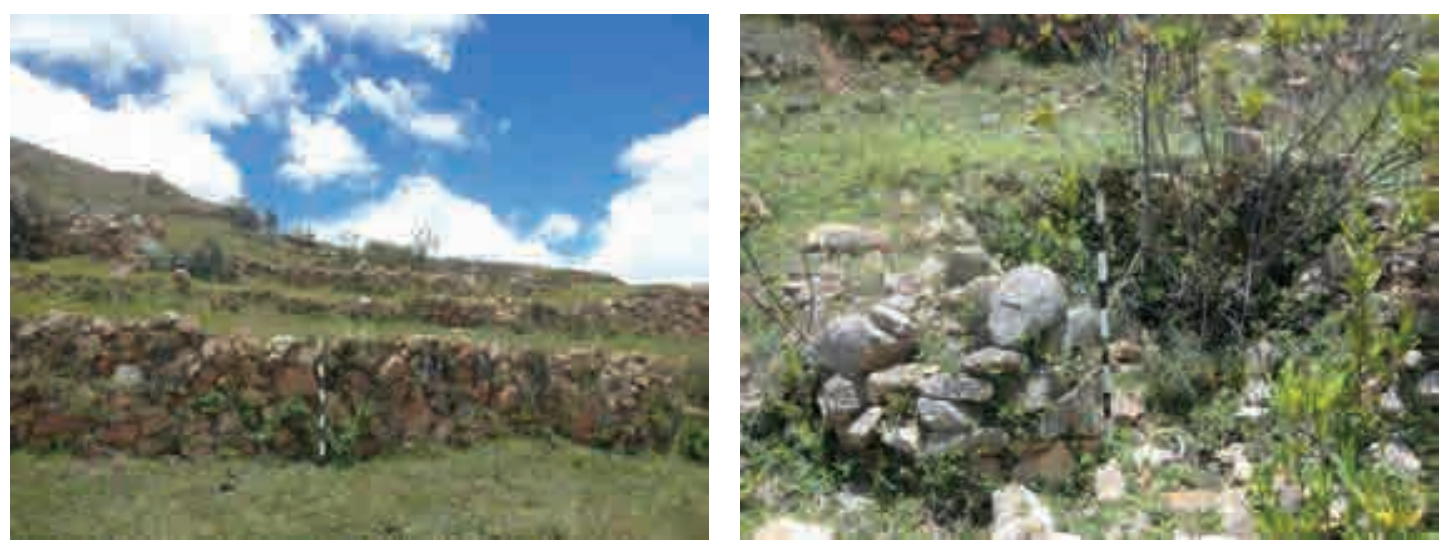

Fig. 3: Izquierda; vista panorámica de andenerías del Sureste. Fig. 4. Derecha: detalle de un recinto de planta circular, sitio Cóndor Rumi. 
sector B: situado a Oeste del sector A, entre la coordenadas UTM: 8524788N y 631202E, a 3040 m.s.n.m., compuesto de andenerías separadas por muros parecidos al sector A y un recinto circular pequeño (tipo tambo) con hornacina (fig. 8), delineado por muros de doble hilera, con relleno de tierra, con un acceso orientado al Norte, tiene de 2.30 a $2.50 \mathrm{~m}$ de diámetro, de 0.30 a $0.60 \mathrm{~m}$ el ancho del muro y de 1 a $1.10 \mathrm{~m}$ el acceso.

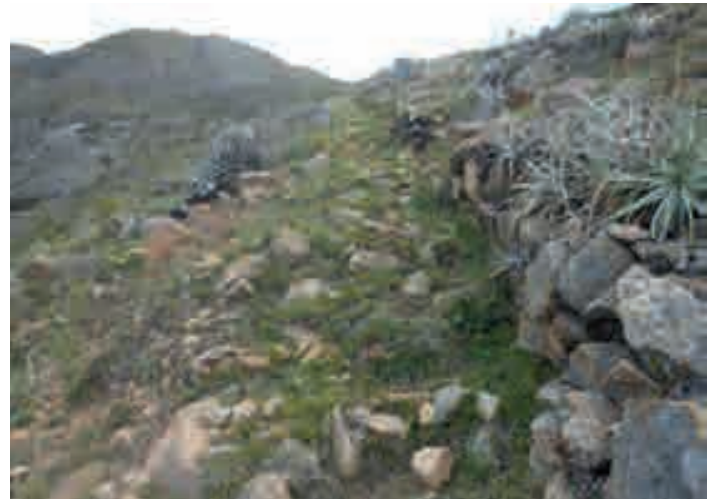

Fig. 5: detalle de una parte del camino.

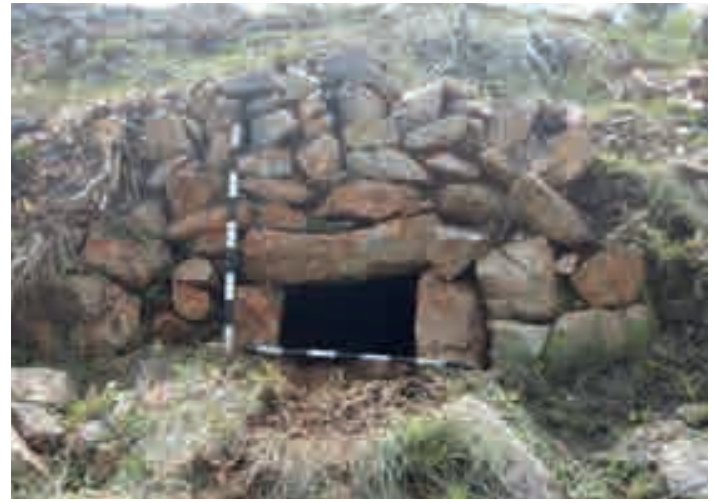

Fig. 6: detalle de la chullpa, sitio Cóndor Rumi.

El sector C: ubicado al lado Sur y Sureste, entre las coordenadas UTM: 8524598N y 631313E, a unos 3026 m.s.n.m.; compuesto de un conjunto de amplias andenerías sobre una planicie, rodeado de abrigos rocosos, pedregales, y grandes árboles de molle, cabuya y tuna; asociado a 3 recintos circulares pequeños (cistas) (fig. 9), delineados por muros de doble hilera (Cista ${ }^{\circ} 2$ ) y de una sola hilera (Cista $\mathrm{n}^{\circ} 1 \mathrm{y} 3$ ), hechas con piedras alargadas dispuestas de forma vertical y horizontal. Tiene de $0.78 \mathrm{~m}$ a $2 \mathrm{~m}$ de diámetro, de 0.15 a $0.75 \mathrm{~m}$ el ancho del muro y de 0.10 a $0.25 \mathrm{~m}$ el alto del muro.

SITIO 03: MISKI RANRA (MR03); ubicado al Noroeste de la comunidad de Chaccchahua a unos 2 $\mathrm{km}$. Consiste en un poblado residencial. Fue dividido en 2 sectores (fig. 10): A y B.

El sector A: está ubicado sobre un montículo en la parte baja (fig. 11), entre las coordenadas UTM: 8523039 N y 629353E, a 2926 m.s.n.m. Este sector está compuesto de: Recintos circulares, de doble hilera de piedras, sin acceso de mampostería ordinaria con relleno de piedras pequeñas, tierra y frag-

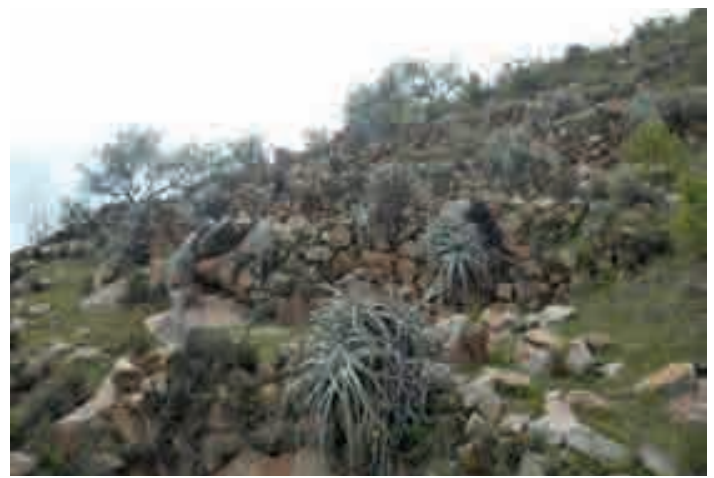

Fig. 7: detalle de andenerías del sector A.

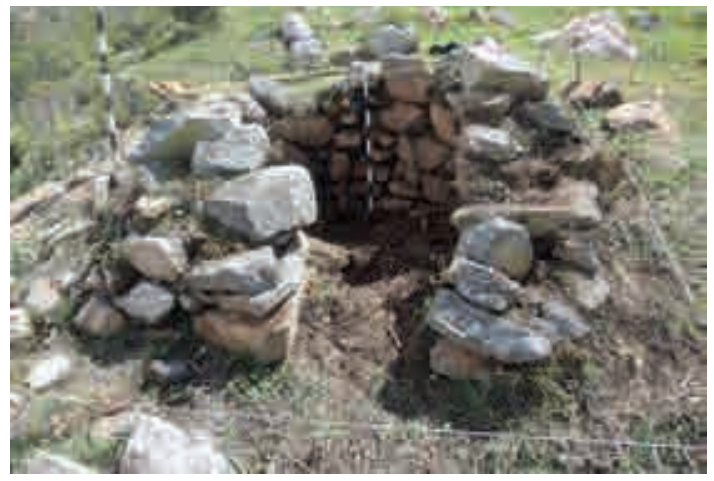

fig. 8: detalle de recinto circular pequeño en el sector $B$. Sitio Chillka Yaku. 
mentos de cerámica (fig. 12). En el interior de corrales grandes de forma semi - rectangular asociados a calles y pasajes. Tienen de 6 a $6.50 \mathrm{~m}$ de diámetro, de $0.60 \mathrm{~m}$ a $1.80 \mathrm{~m}$ de altura. Corrales: recintos semi - cuadrangulares con acceso, de muros de doble hilera de mampostería ordinaria con relleno de tierra, piedras pequeñas y cerámica, dentro existe una o mas recintos circulares. Tienen de 10 a $12 \mathrm{~m}$ de ancho de 12 a $12.50 \mathrm{~m}$ de largo y de 1 a $1.20 \mathrm{~m}$ de altura el muro.

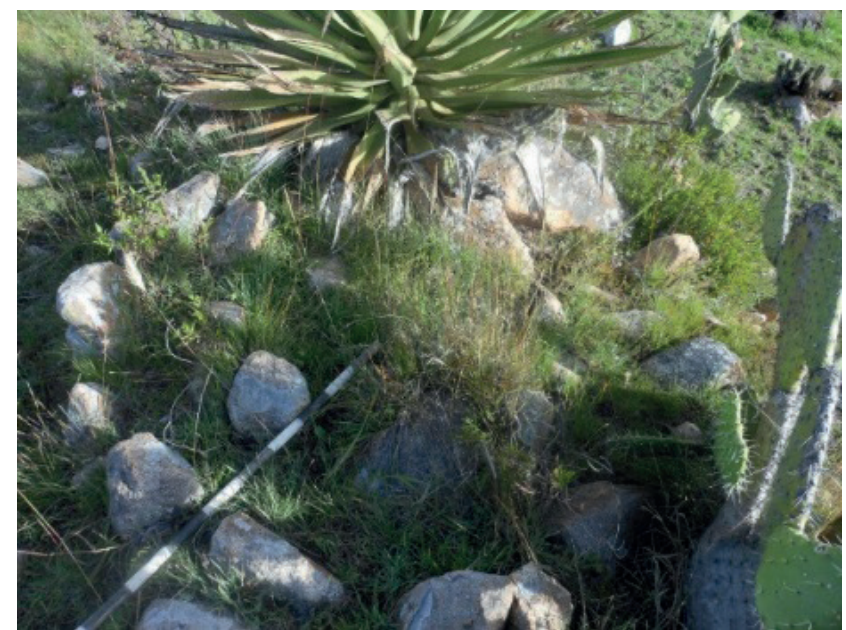

Fig. 9: vista en detalle de una Cista, sector C, sitio Chillka Yaku.

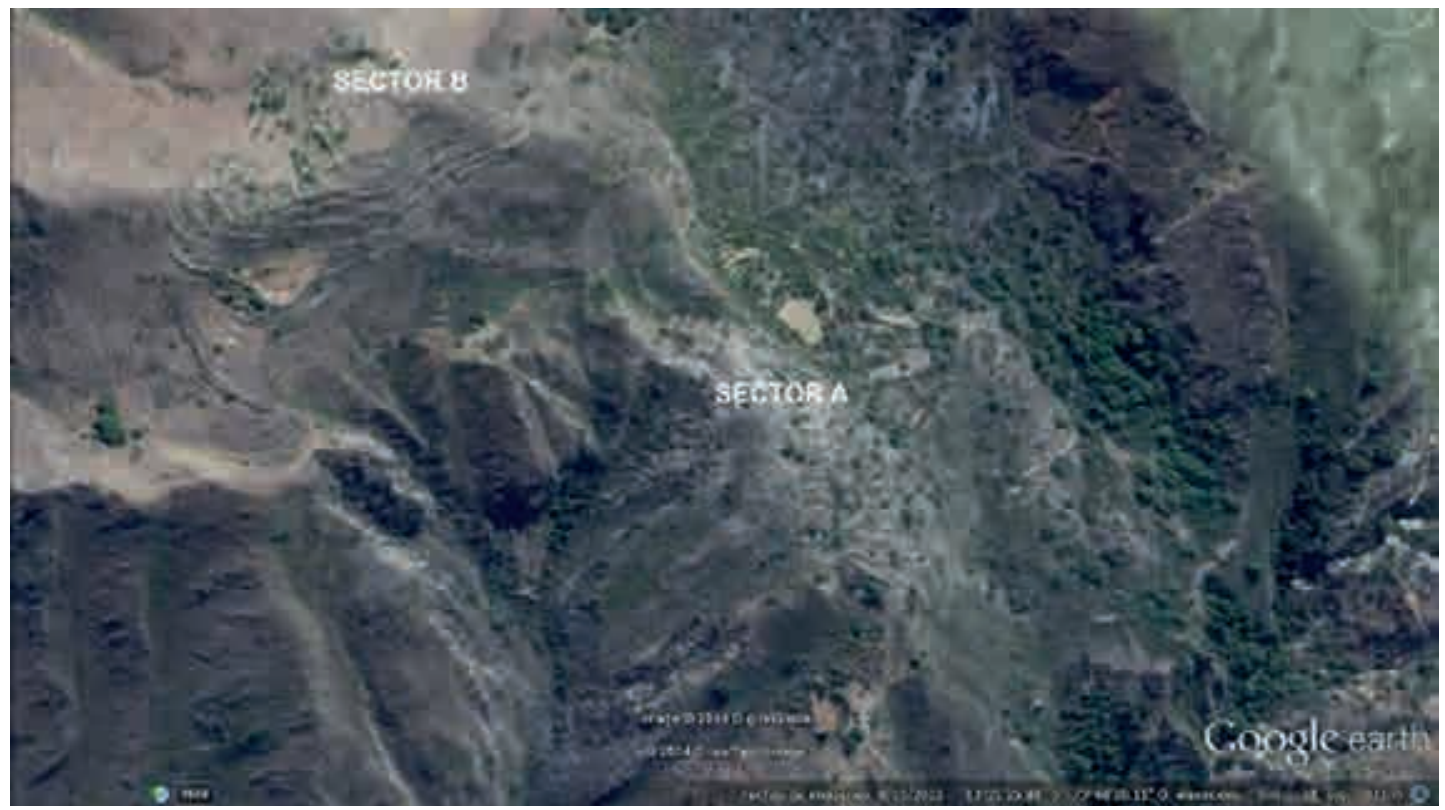

Fig. 10: Vista satelital de los dos sectores (A y B) del sitio Miski Ranra. 
Murallas; existen 3 murallas ubicadas alrededor del montículo del sector A, formadas por muros de doble hilera con acceso al Noroeste (fig. 13), de corte trapezoidal, con base ancha y parte superior angosta, de mampostería ordinaria sin argamasa; con relleno de tierra, piedras pequeñas y cerámica. La parte superior de la muralla presenta ventanas sin dintel, de los cuales solo se conservan 7 de ellos. La parte interna (fig. 14) presenta una plataforma de circulación, con escalinatas de 3 a 4 piedras embutidas. Tiene de 2.60 a $3.80 \mathrm{~m}$ de altura, de 1.20 a $2.60 \mathrm{~m}$ de ancho y de 80 a $350 \mathrm{~m}$ de largo.

Piedras embutidas: son un conjunto de 12 y 7 piedras alargadas, embutidas en la parte media del paramento de un muro (fig. 15), inclinado en $45^{\circ}$. Y por último, Andenes, ubicados en los exteriores

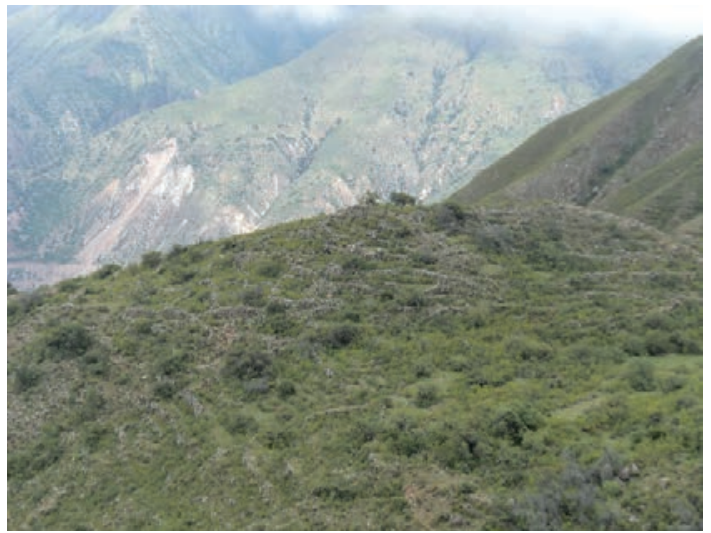

Fig. 11: Vista panorámica del sector A.

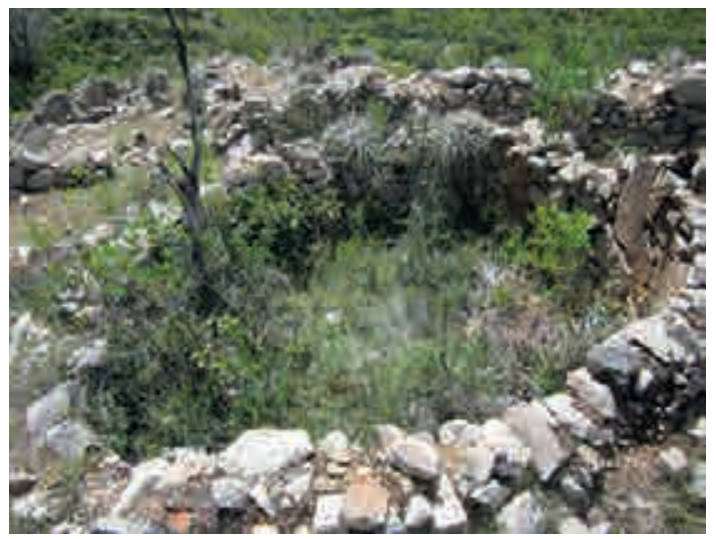

Fig. 12: detalle de un recinto circular sin acceso, sitio Miski Ranra, sector A.

del sector A (fig. 16); hechos con mampostería ordinaria, separados de muros de doble hilera, con relleno de tierra, fragmentos de cerámica, y piedras pequeñas. Tienen de $1 \mathrm{a} 1.20 \mathrm{~m}$ de altura, de $10 \mathrm{a}$ $15 \mathrm{~m}$ de largo y de 1.50 a $3 \mathrm{~m}$ la distancia de un anden a otro.

Sector B: ubicado al Noroeste del sector A, entre las coordenadas UTM: 8523299N y 629038E a 3028 m.s.n.m., compuesto de corrales amplios con recintos circulares en el interior (fig. 17), andenes divididos por muros (fig. 18), murallas con zanjas, con características similares al sector A.

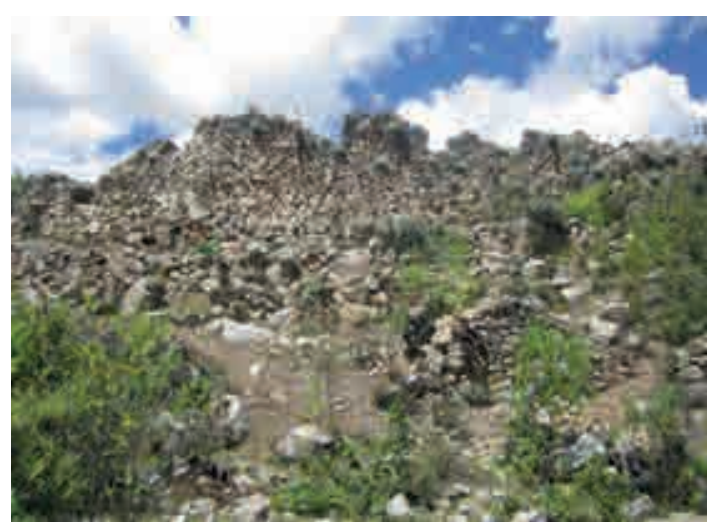

Fig. 13: Vista anterior de la muralla Noroeste.

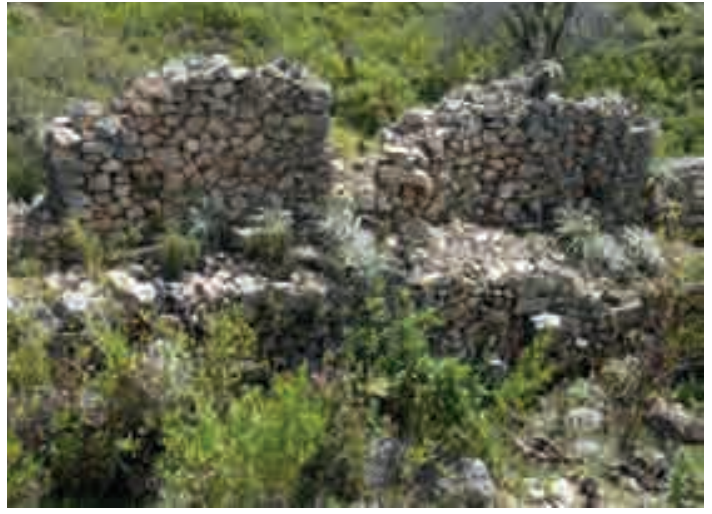

Fig. 14: detalle de la parte posterior de la muralla Noroeste, sitio Miski Ranra, sector A. 
SITIO 04: YURAQ TUNAS (YT04); ubicado al Este de la comunidad de Chaccchahua. Está dividido en 3 sectores: A, B y C. El Sector A: ubicado entre las coordenadas UTM: 8523952N y 631538E a 3215 m.s.n.m., compuesto de andenerías (fig. 19), de mampostería ordinaria; orientados de Este a Oeste, separados por 3 muros de doble hilera con relleno de piedras pequeñas y tierra. Tienen de $0.80 \mathrm{~m} \mathrm{a}$ $1.20 \mathrm{~m}$ de altura, de 8 a $10 \mathrm{~m}$ de largo y de 1.70 a $2.10 \mathrm{~m}$ la distancia de andén a otro. El sector B, si-

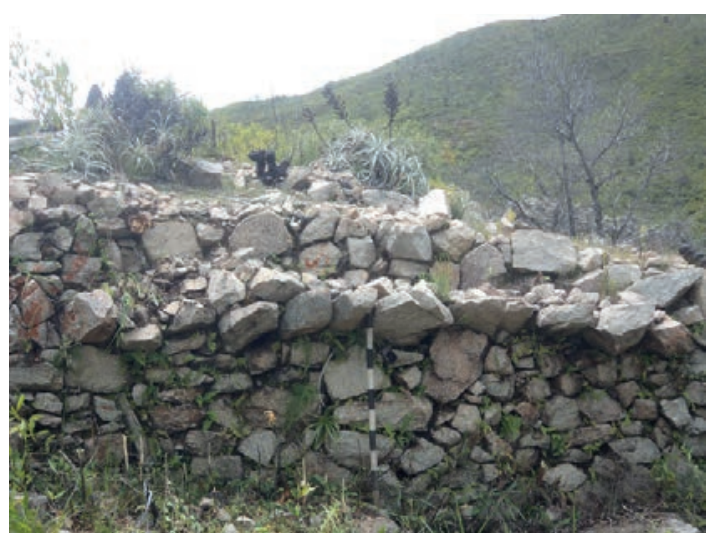

Fig. 15: detalle de las piedras embutidas.

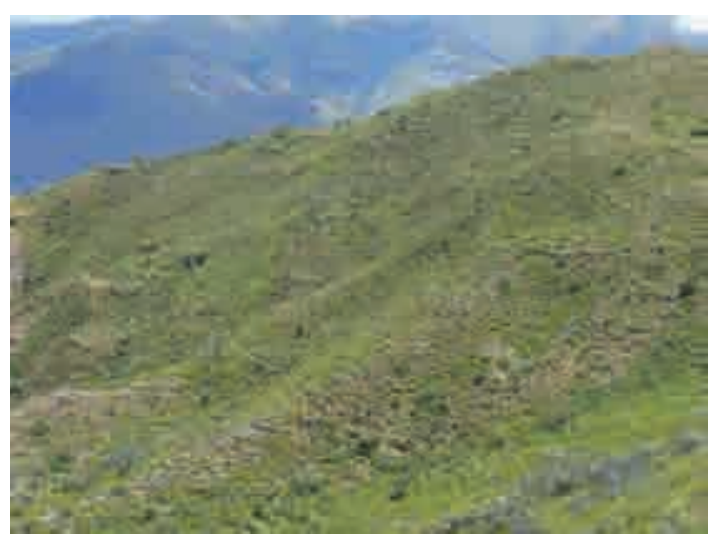

Fig. 16: vista panorámica de las andenerías del lado Noroeste del sector A, sitio Miski Ranra.

tuado al Noroeste del sector A, entre las coordenadas UTM: 8524042N y 631432E a 3220 m.s.n.m., en una pequeña hondonada, igualmente compuesta de andenerías, más conservados y la distancia entre andén es más extenso (fig. 20). Tienen de $0.80 \mathrm{~m}$ a $1.40 \mathrm{~m}$ de altura, de 5 a $15 \mathrm{~m}$ de largo y de 2.30 a 6 $m$ la distancia de andén a otro.

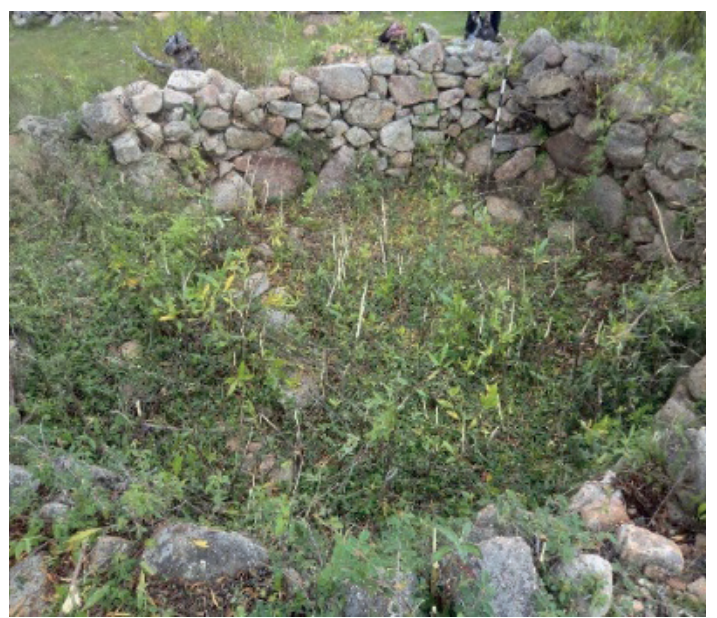

Fig. 17: detalle de un recinto circular.

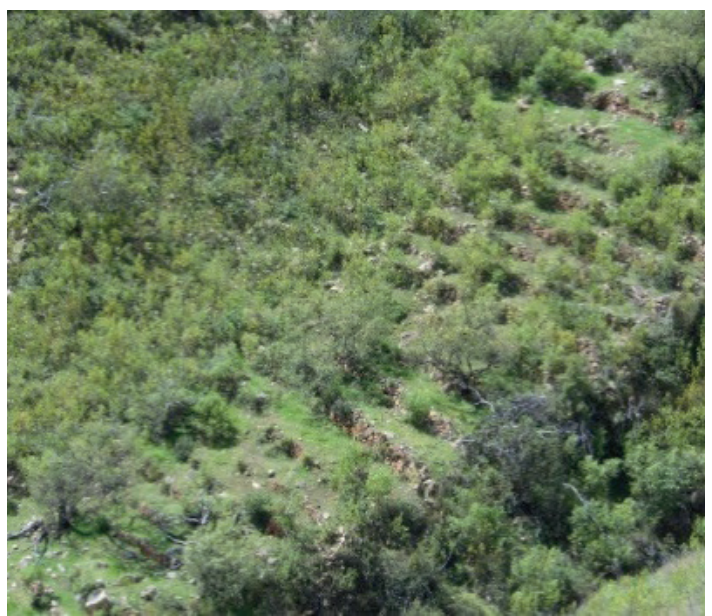

Fig. 18: vista panorámica de las andenerías del sector B, sitio Miski Ranra. 
El sector C, ubicado al Suroeste del sector A; entre las coordenadas UTM: 8523994N y 631111E a 3240 m.s.n.m., compuesto de extensas andenerías sobre una pequeña hondonada (fig. 21) de mampostería ordinaria, y recintos circulares (cistas), compuestos de muros de una sola hilera, dispuestos de forma horizontal, con acceso orientado hacia el Sur (fig. 22).

SITIO 05: MINAS PATA (MP05); ubicado al Noreste de la comunidad de Chaccchahua, en la frontera con la comunidad de Yanavilca; entre las coordenadas UTM: 8523432N y 631059E a 3495 m.s.n.m. Este sitio está compuesto de: recintos circulares, formado por muros de doble hilera, con relleno de tierra y piedras pequeñas, de mampostería ordinaria (fig. 23) sin acceso. Tienen de 6 a $8 \mathrm{~m}$ de diámetro, de 0.80 a $1.20 \mathrm{~m}$ la altura del muro y de 0.50 a $1.10 \mathrm{~m}$ el ancho del muro. Murallas y zanjas: ubicado

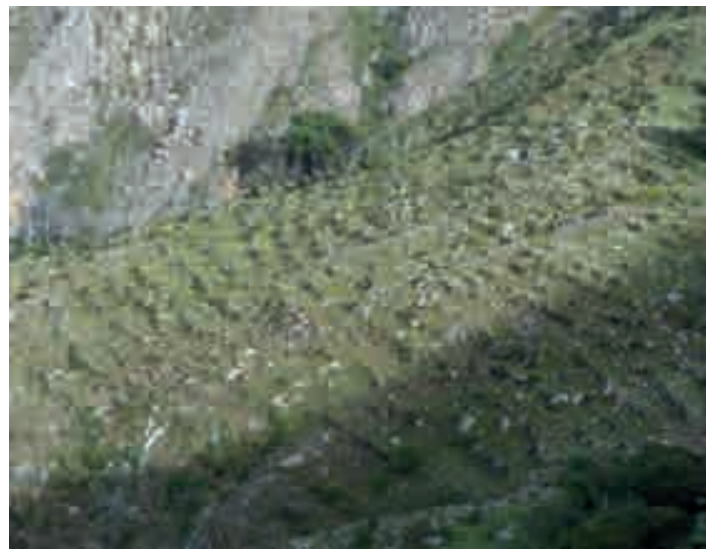

Fig. 19: Vista panorámico de andenerías del sector A.

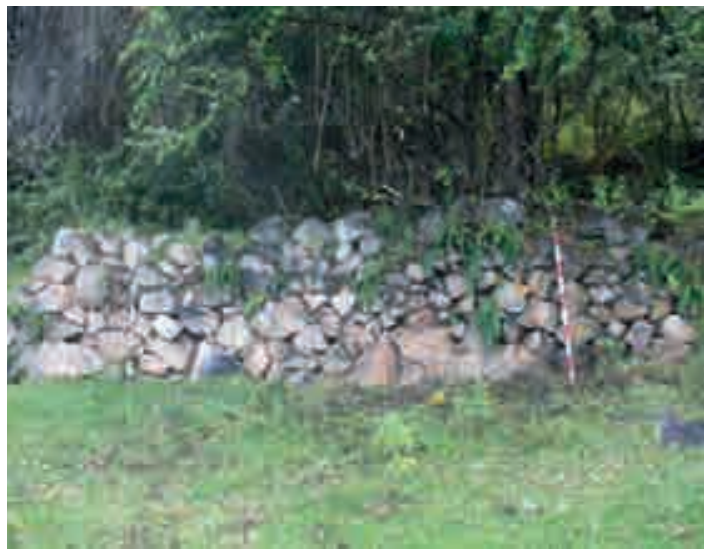

Fig. 20: detalle de una andenería del sector B, sitio Yuraq Tunas.

al Norte y Sur del sitio, a unos 100 metros, compuesta de muros de doble hilera, de mampostería ordinaria, asociado a zanjas hacia el exterior (fig. 24). Tiene $100 \mathrm{~m}$ de largo aprox., 0.60 a 1.10 el ancho del muro y 0.80 a $1 \mathrm{~m}$ el ancho del muro.

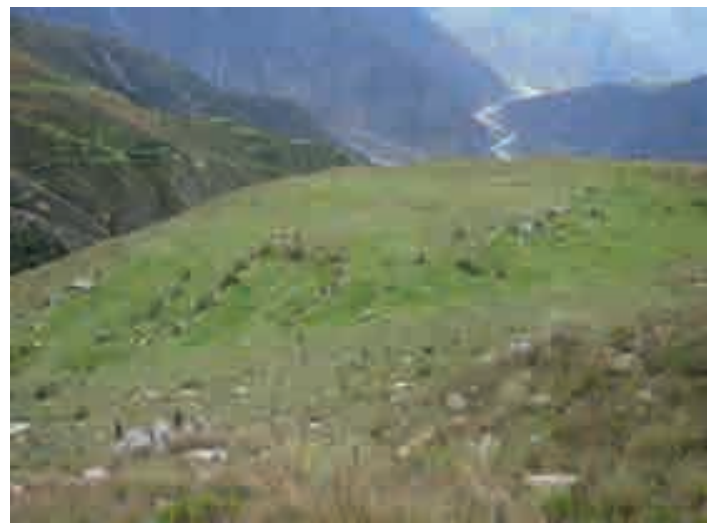

Foto 21: Vista panorámico de andenerías.

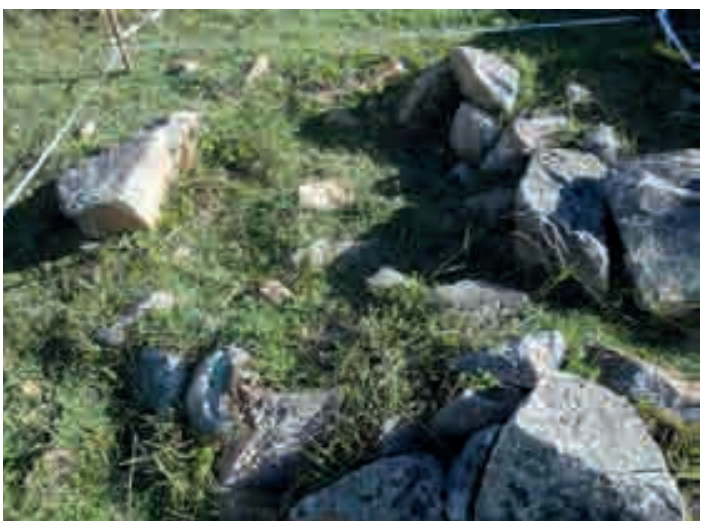

Fig. 22: detalle de un recinto circular pequeño, sitio Yuraq Tunas, sector $C$. 
SITIO 06: RANRAKUCHU (RK06); ubicado a unos $500 \mathrm{~m}$, al Noroeste de la comunidad de Chaccchahua, a unos 3401 m.s.n.m. entre la coordenadas UTM: 8523573N y 631294E; compuesto de una chullpa con paravientos en el acceso orientado al Este (fig. 25), con una zona de entierro colectivo, ubicado debajo de una roca de unos 4 metros de altura y 7 metros de ancho, en el cual se ha implementado una estructura circular compuesta de muros de una sola hilera, con 3 o 4 piedras como máximo, dentro del cual se hallan restos óseos de 14 individuos sobre una intrusión en el piso, como cráneos con deformaciones, fémures, costillas, etc. El interior de la chullpa (fig. 26) tiene $1.40 \mathrm{~m}$ de ancho, $0.40 \mathrm{~m}$ de altura y $1.70 \mathrm{~m}$ de profundidad. Está asociado a andenes y algunos recintos circulares en los alrededores.

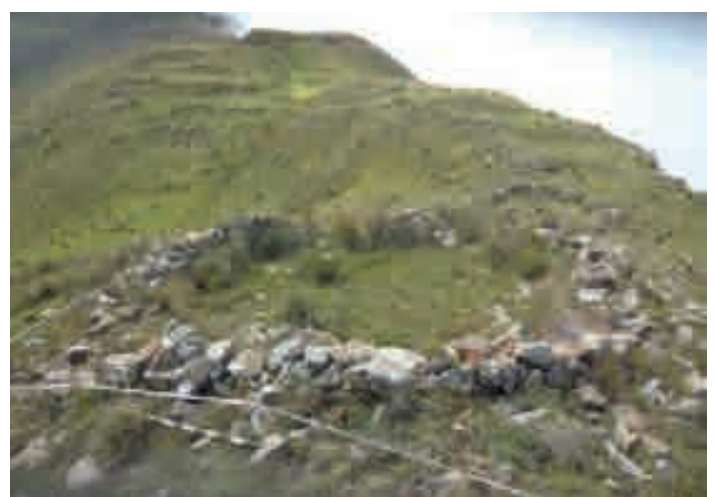

Fig. 23: detalle de un recito circular.

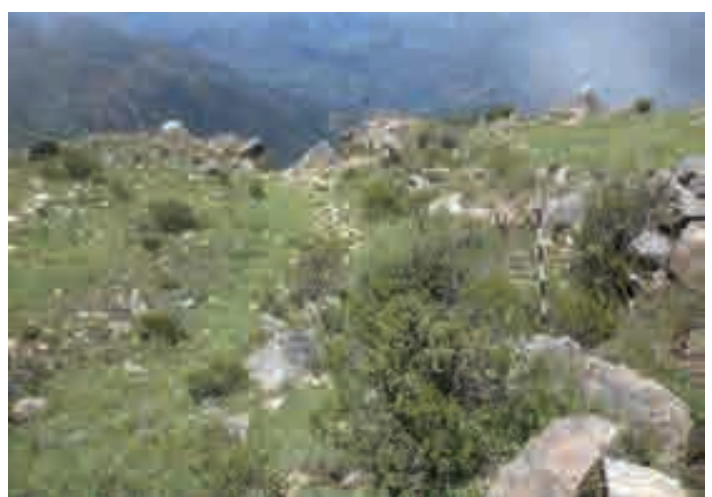

Fig. 24: detalle de la muralla sur adosado a una zanja en la parte externa, sitio Minas Pata.

SITIO 07: CHAWPI CHUKLLA (CH07); ubicado al Noroeste de la comunidad de Chaccchahua, entre las coordenadas UTM: 8523032N y 631655E a 3482 m.s.n.m., compuesto de amplias andenerías orientados de Este a Oeste, de mampostería ordinaria (fig. 27); tienen de $0.80 \mathrm{~m}$ a $1 \mathrm{~m}$ de altura, $15 \mathrm{a}$ $18 \mathrm{~m}$ de largo y de 13 a $15 \mathrm{~m}$ la distancia de andén a otro. Además de una cueva, formada en una roca grande de $6 \mathrm{~m}$ de alto, $4 \mathrm{~m}$ de ancho y $5 \mathrm{~m}$ de largo, debajo del cual se encuentra una abertura amplia con un piso, con 3 piedras planas dispuestas de forma vertical (especie de paraviento), asociado a fragmentos de cerámica y restos óseos (fig. 28). El interior tiene $3.50 \mathrm{~m}$ de largo, $16 \mathrm{~m}$ de altura y $5 \mathrm{~m}$ de profundidad.

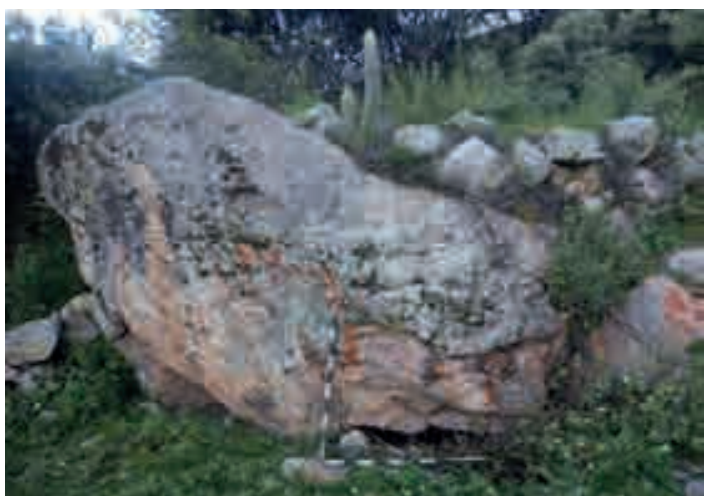

Fig. 25: detalle del exterior de la chullpa.

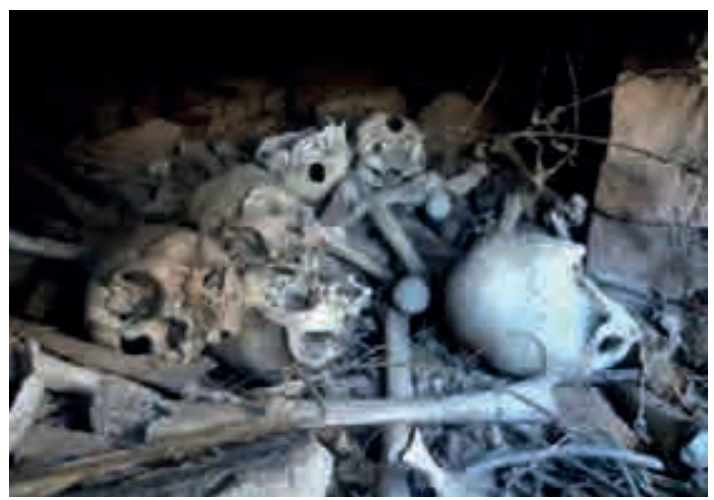

Fig. 26: detalle del interior con restos óseos, sitio Ranrakuchu. 
SITIO 08: MULLAKA PATA (MPA08); situado al Noreste de la comunidad de Chacchahua, a $3 \mathrm{~km}$ de distancia, a 3525 m.s.n.m. entre las coordenadas UTM: 8522803N y 0631095E, está compuesto únicamente por 16 recintos de planta circular de muros de doble hilera (solo se conservan las cabeceras de muro), dispuestos de forma horizontal con relleno de piedras pequeñas y tierra (fig. 29); unidos en algunos casos con muros de doble hilera. Tienen de 5.80 a $7 \mathrm{~m}$ el diámetro y de $0.80 \mathrm{~m}$ a $1 \mathrm{~m}$ el ancho del muro. Además, existe la presencia de corrales, al Sur y Noroeste, formado por muros de una sola hilera, dispuestas de forma horizontal y vertical (fig. 30), de 10.50 a $12 \mathrm{~m}$ el diámetro, de 1 a $1.20 \mathrm{~m}$ la altura del muro y de 0.15 a $0.20 \mathrm{~m}$ el ancho del muro.

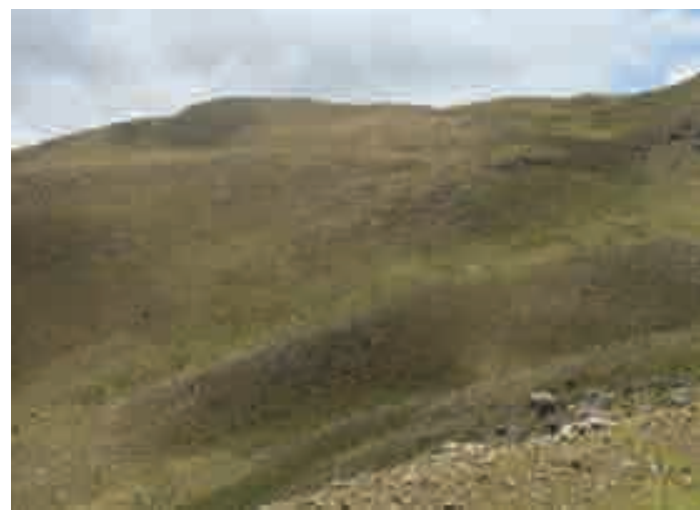

Fig. 27: Vista panorámica de las andenerías.

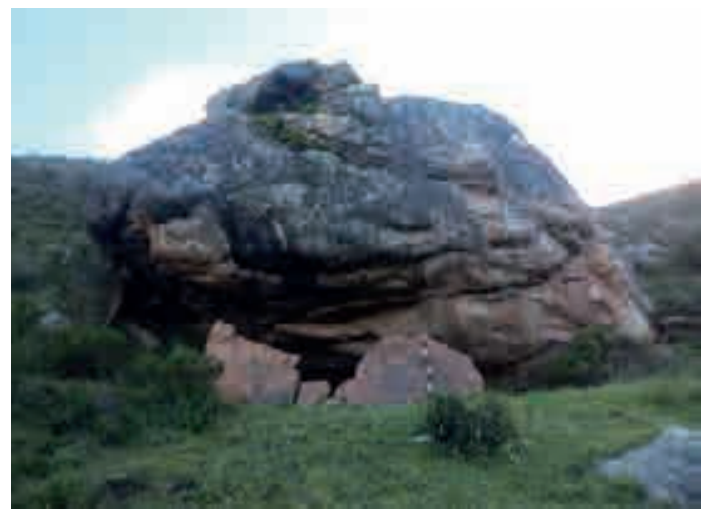

Fig. 28: detalle de la cueva, sitio Chawpi Chuklla.

SITIO 09: RAQA RAQAY (RR09); ubicado al Este de Chaccchahua, a $3 \mathrm{~km}$. Este sitio está dividido en 2 sectores: A y B. El Sector A; ubicado entre las coordenadas UTM: 8522028N y 0632853E a 3810 m.s.n.m.; es el sector con mayor extensión, compuesto de: recintos circulares en el interior de corrales grandes con acceso a una calle principal o secundaria. Existen dos tipos de recintos circulares: simples (fig. 31), formados por muros de doble hilera, de mampostería ordinaria, asociado a batanes, mano moliendas y gran cantidad de morteros en el interior y exterior de la misma: dobles (fig. 32); tienen adosados otro recinto circular en media luna en el interior. Tienen de 5 a $5.20 \mathrm{~m}$ de diámetro, de 0.60 a $0.80 \mathrm{~m}$ el ancho y de $0.80 \mathrm{~m}$ a $2 \mathrm{~m}$ la altura del muro.

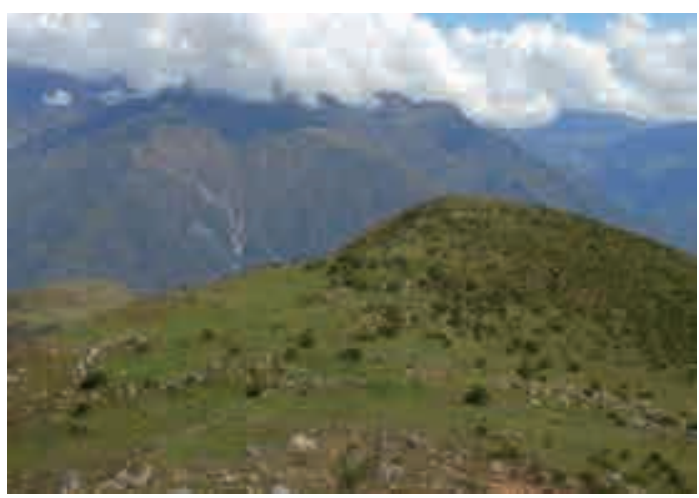

Fig. 29: Vista panorámico de los recintos circulares.

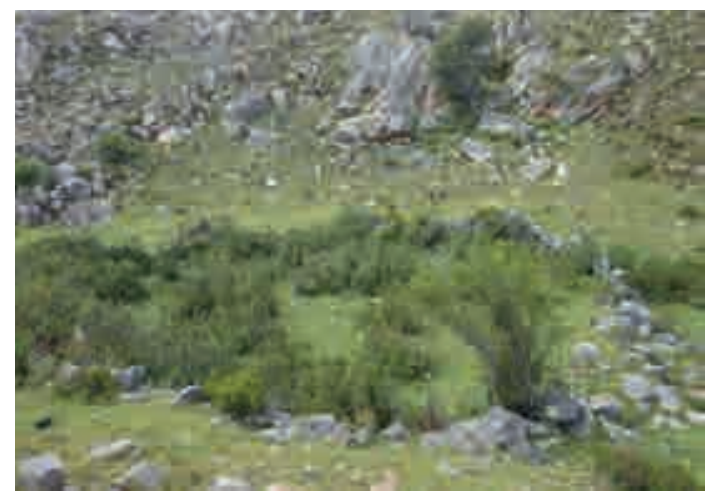

Fig. 30: detalle de un corral, sitio Mullaka Pata. 
Las calles principales y secundarias: Las calles principales, recorren el sitio hasta la parte media y las calles secundarias están ubicadas en todo el asentamiento, parten de las calles principales e ingresan a los corrales con recintos circulares (fig. 33). Todas están delineadas por muros de doble hilera con relleno de tierra y piedras pequeñas, de mampostería ordinaria. Tienen de $0.80 \mathrm{~m}$ a 2.50 $\mathrm{m}$ de ancho, de 1 a $2.10 \mathrm{~m}$ de altura y de 1 a $1.30 \mathrm{~m}$ el ancho del muro. Murallas y zanjas: ubicadas al Sur y Norte - Noroeste. Al Sur existen 6 murallas (fig. 34), asociadas a zanjas, compuesta de muros de doble hilera con relleno de piedras pequeñas y hormigón. Tienen de 1.20 a $1.80 \mathrm{~m}$ de altura, de $0.80 \mathrm{a}$ $1.20 \mathrm{~m}$ el ancho del muro y de 15 a $120 \mathrm{~m}$ el largo aprox. Mientras tanto la zanja, de $1 \mathrm{a} 2 \mathrm{~m}$ de ancho y de 1 a 1.30 m de profundidad.

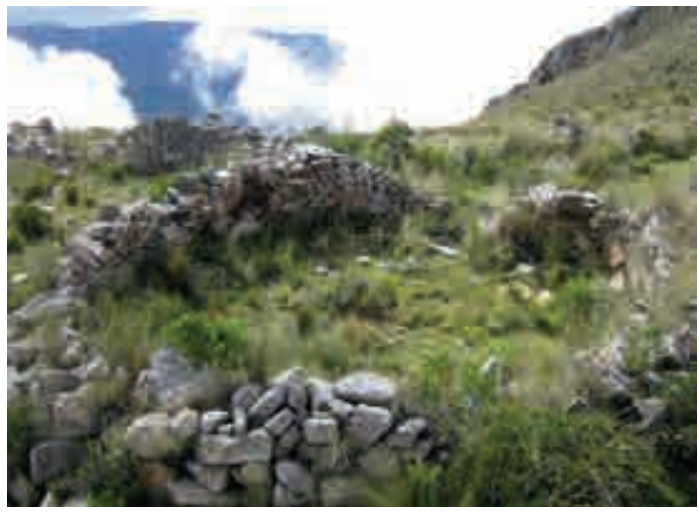

Fig. 31: detalle de un recinto circular simple.

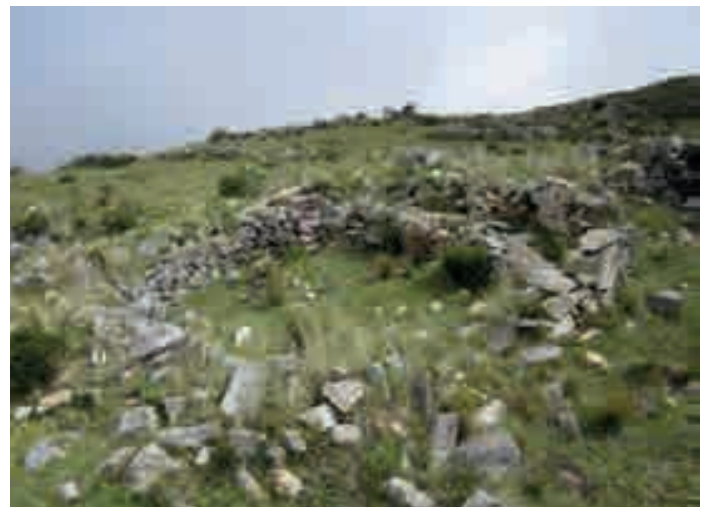

Fig. 32: detalle de un recinto doble, sitio Raqa Raqay, sector A.

Ushnu, ubicado en la parte más alta al Sur del sitio (fig. 35), compuesta de una estructura rectangular de una sola plataforma con acceso al Sur, de muros de doble hilera en la parte alta, de mampostería ordinaria. Asociado a cistas y un muro en la parte superior. Tiene $12.70 \mathrm{~m}$ de ancho, $13.50 \mathrm{~m}$ de ancho y de 1.20 a $1.50 \mathrm{~m}$ de altura del muro. Abrigo rocoso: ubicado al Este del sitio (fig. 36), debajo de una formación rocosa, en una intrusión en la roca, asociado a materiales cerámicos (bordes, fragmentos del cuerpo, piruro y otros) y óseos (costillas, parte frontal del cráneo, fémur, dientes, y otros). Tiene $4.30 \mathrm{~m}$ de ancho, de 1 a $2.40 \mathrm{~m}$ de altura y de 2 a $5 \mathrm{~m}$ de profundidad.

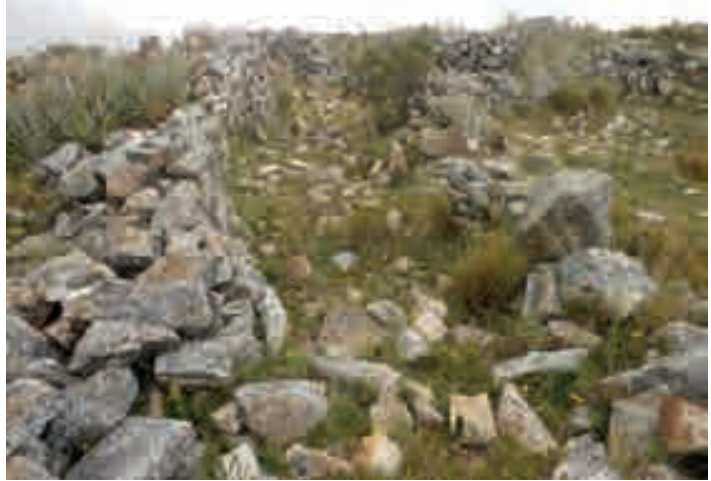

Fig. 33: detalle de una calle principal.

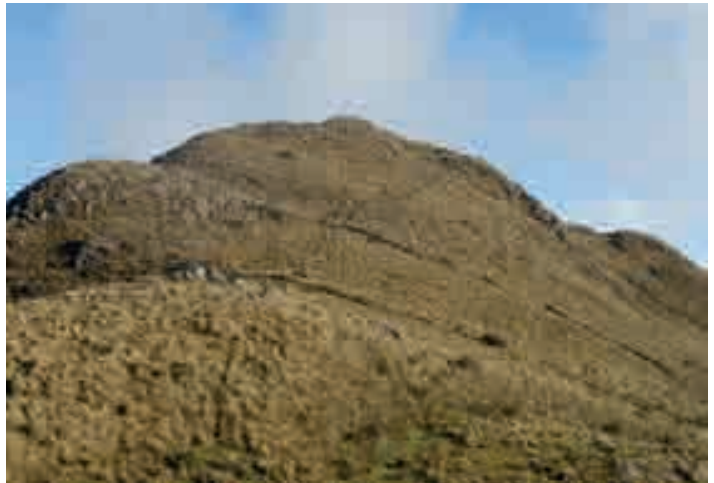

Fig. 34: vista panorámica de las tres murallas lado Sur, sitio Raqa Raqay, sector A. 
Sector B; situado al Noreste del sector A, entre las coordenadas UTM: 8522019 N y 0632310 E a 3795 m.s.n.m., conformado de recintos circulares en el interior de corrales (fig. 37), murallas, zanjas, pequeños pasajes entre los corrales, un montículo de piedras amontonadas, con características constructivas similares al sector A.

SITIO 10: TARAPAMPA (TP10); ubicado al Noroeste de Chaccchahua (fig. 38), a 3071 m.s.n.m. entre las coordenadas UTM: $8523450 \mathrm{~N}$ y 0629853E. Está compuesto de: andenerías separadas por muros (fig. 39), asociado a recintos circulares, hechos de mampostería ordinaria, además, asociados a montículos trapezoidales. Tienen de $0.80 \mathrm{~m}$ a $1.50 \mathrm{~m}$ de altura, de 12 a $20 \mathrm{~m}$ de largo y de 3 a $4 \mathrm{~m}$ la distancia de andén a otro.

Recintos circulares, situados sobre los andenes (fig. 40), compuesto de muros de doble hilera con relleno de tierra y piedras pequeñas, algunos recintos presentan hornacina. Tiene de 5.10 a $5.40 \mathrm{~m}$ de

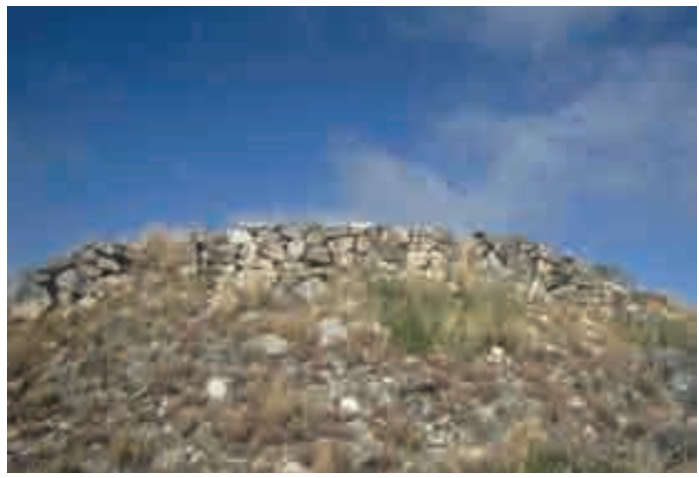

Fig. 35: detalle del ushnu visto desde el sur.

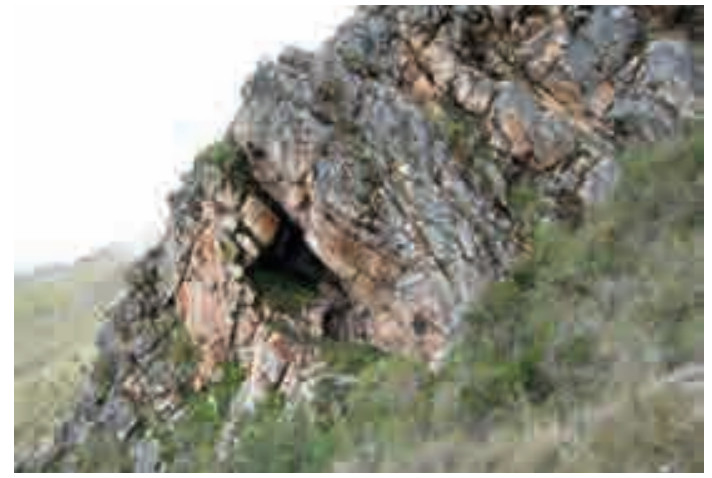

Fig. 36: detalle del abrigo rocoso, sitio Raqa Raqay, sector $A$

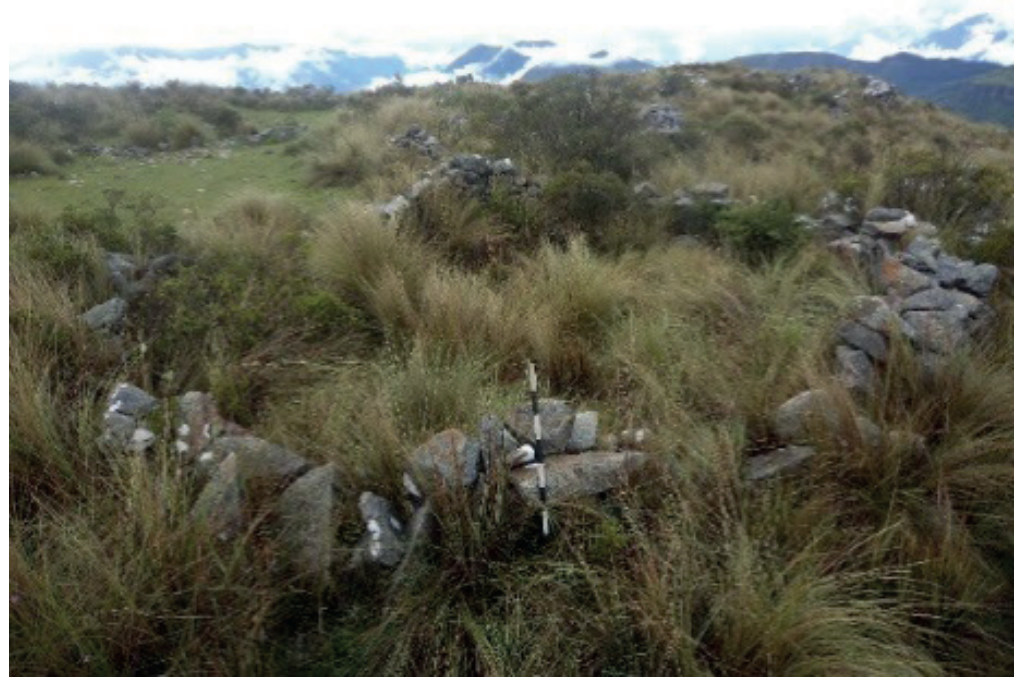

Fig. 37: detalle de un recinto circular del sector B de Raqa Raqay. 
diámetro, de 1.20 a $1.40 \mathrm{~m}$ la altura del muro y de 0.40 a $0.80 \mathrm{~m}$ el ancho del muro. Cistas, 6 recintos pequeños ubicados al Este (fig. 41), compuestas de muros de una sola hilada, con piedras alargadas dispuestas de forma horizontal orientados hacia el interior del recinto. Tienen de 2.10 a $2.20 \mathrm{~m}$ de diámetro y de 0.20 a $0.30 \mathrm{~m}$ de ancho del muro.

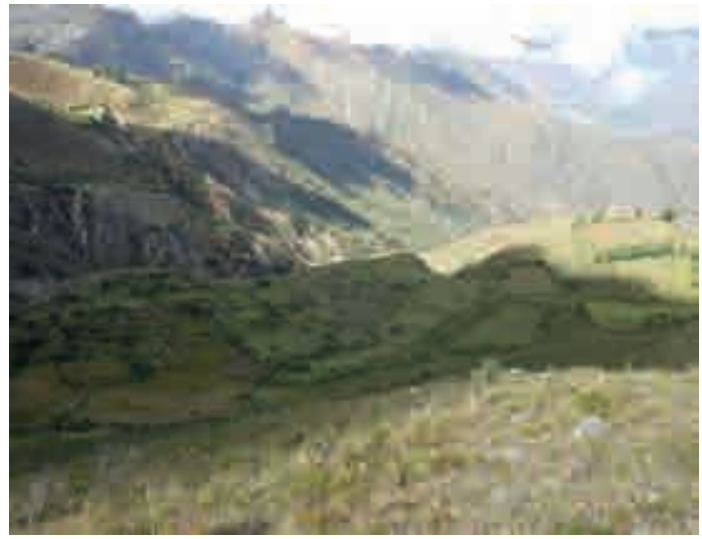

Fig. 38: Vista panorámico del sitio Tarapampa.

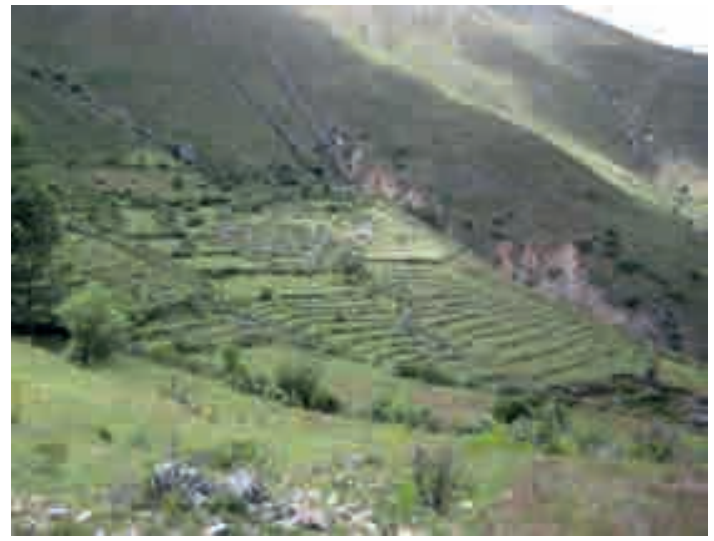

Fig. 39: detalle de andenerías, del sitio Tarapampa.

\section{Discusión}

Tras el colapso del Horizonte Medio, surge una nueva forma de organización durante el Intermedio tardío (1000 a.C. - 1400 a.C.), en los actuales territorios de Huancavelica, Ayacucho y Apurímac, ligado a una organización social, política, cultural y de asentamiento muy distinto al Horizonte Medio. Esta nueva forma de organización, no seguía la tradición de sus antecesores los Wari (Lumbreras 1974). Estaban organizados en pequeños grupos aislados y aglutinados en áreas muy reducidas y escarpados. Es entonces, que dejan las grandes urbes para asentarse en pequeñas aldeas, dedicado a una vida rural y campesina (Gonzales 1992). Sin embargo, Gamarra (1995) considera que los chancas corresponden a una población marginal y contemporánea a los wari, y que continuó subsistiendo tras el colapso del mismo.

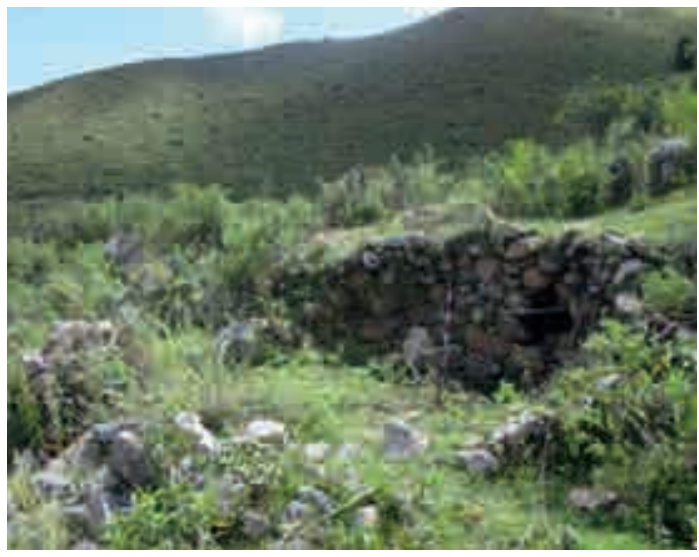

Fig. 40: detalle de un recinto circular.

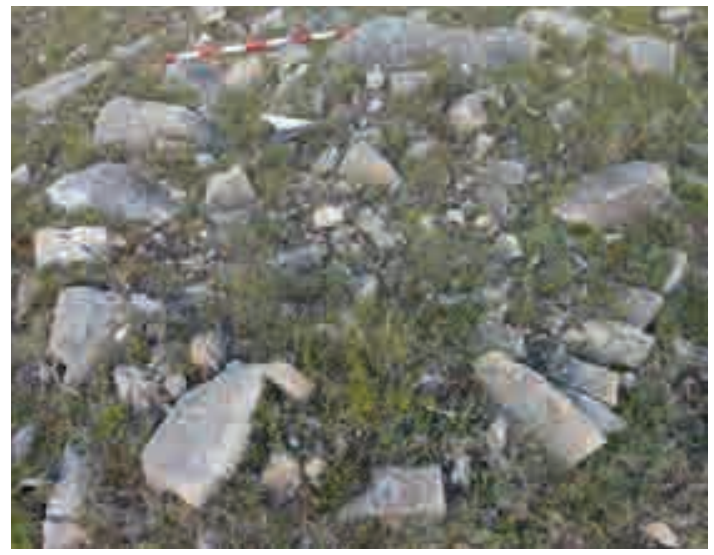

Fig. 41: detalle de uno de los pequeños recinto circulares (cistas), sitio Tarapampa. 
Estas pequeñas aldeas estaban situadas en lugares con difícil acceso, rodeado de fuertes pendientes, quebradas profundas y a veces, rodeado de fuertes farallones; sin embargo, existe una serie de razones que permitió elegir estos lugares; una razón netamente estratégica y política (González 1992). Por otro lado, los trabajos realizados por Grossman en Andahuaylas, concluye que la ubicación de los yacimientos responde a prioridades económicas, así como la defensa y protección de un desastre natural (Grossman 1983:48, citado por Bauer 2010: 107). Para Bauer (2010), para el establecimiento de estos sitios existe una respuesta multicausal, entre causas sociales, políticas y económicas.

Los resultados de las investigaciones arqueológicas, en la frontera Este, Norte y Noroeste de la comunidad de Chaccchahua, distrito Huaccana, dan cuenta de una continua ocupación desde el Formativo hasta el Horizonte Tardío, con una mayor ocupación durante el Intermedio Tardío, por la mayor cantidad de evidencias encontradas. Estas evidencias acumuladas permitieron identificar los sitios, con un patrón arquitectónico complejo y muy bien organizado, que corresponden a poblados residenciales fortificados, compuestos de recintos habitacionales (de planta circular y cuadrangular), andenerías (divididos por muros) estructuras con fines defensivos (murallas y zanjas), funerarios (chullpas, cistas y abrigos rocosos), de almacenamiento (tambos y pequeños recintos circulares), ceremoniales (ushnus y plataformas en la cima de los cerros), y estructuras de circulación (calles principales y secundarias) (fig. 42), todos ellos asociados a material cultural, como cerámica y líticos.

La distribución de estos tipos de estructuras sugieren a aldeas diferentes dentro de una misma época prehispánica, el Intermedio Tardío, con algunas diferencias y similitudes.

En los asentamientos situados en las partes bajas (fig. 42), las andenerías, son terrazas extensas, ubicadas en los exteriores de los sitios, separados por muros perpendiculares, de doble hilera con relleno de tierra, piedras pequeñas y fragmentos de cerámica, recurrentes en Miski Ranra, Cóndor Rumi, Chillka Yaku y Tarapampa. Los recintos habitacionales (de planta circular y cuadrangular) sin acceso, están en el interior de corrales de distintas dimensiones y formas, divididos por calles principales y secundarias (delineados por muros de doble hilera) presentes en Miski Ranra, Cóndor Rumi y Tarapampa. Las estructuras con fines defensivos (murallas y zanjas), se evidencian en los exteriores de los sitios, consisten en muros de doble hilera adosados de una zanja en la parte externa.

\begin{tabular}{|c|c|c|c|c|c|c|c|c|c|c|}
\hline & \multicolumn{5}{|c|}{ SITIOS DE LA PARTE BAJA } & \multicolumn{5}{|c|}{ SITIOS DE LA PARTE ALTA } \\
\hline ARQUITECTURA & $\begin{array}{l}\frac{8}{3} \\
\frac{\gamma}{1} \\
\bar{\delta} \\
\frac{1}{8}\end{array}$ & 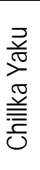 & $\begin{array}{l}\frac{0}{2} \\
\frac{10}{10} \\
\frac{1}{7} \\
\frac{\nabla}{n} \\
\sum\end{array}$ & $\begin{array}{l}n \\
\frac{n}{6} \\
5 \\
\bar{\delta} \\
\frac{0}{2} \\
\gamma\end{array}$ & 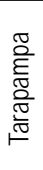 & $\begin{array}{l}\frac{10}{10} \\
0 \\
8 \\
\frac{8}{2}\end{array}$ & 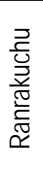 & 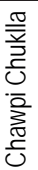 & $\begin{array}{l}\frac{9}{10} \\
\frac{0}{0} \\
\frac{9}{10} \\
\frac{10}{5}\end{array}$ & 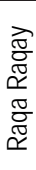 \\
\hline Andenerías & $X$ & $x$ & $x$ & $x$ & $x$ & & $x$ & $X$ & & $x$ \\
\hline Recintos Habitacionales & $X$ & & $x$ & & $x$ & $x$ & & & $x$ & $X$ \\
\hline Murallas y Zanjas & & & $X$ & & & $x$ & & & & $X$ \\
\hline Calles & & & $x$ & & $x$ & & & & & $x$ \\
\hline Caminos & $x$ & & & & & & & & & $x$ \\
\hline Abrigos Rocosos & $x$ & & & & & & & $x$ & & $x$ \\
\hline Chullpas & $x$ & & & & & & $x$ & & & \\
\hline Pequeños Recintos Circulares & & $x$ & & $x$ & $x$ & & & & & \\
\hline Ushnus & & & & & & & & & & $x$ \\
\hline Cistas & & & $x$ & $x$ & $x$ & & & & & $X$ \\
\hline
\end{tabular}

Fig. 42: distribución de las evidencias de los sitios registrados de acuerdo a su ubicación. 
En los asentamientos de las partes altas (fig. 42), las andenerías, son terrazas menos extensas, ubicadas en los exteriores de los sitios, asociado a extensas planicies, en las que no fue necesario el uso de andenerías, estos mismos están presentes en Ranrakuchu, Chawpi Chuklla y Raqa Raqay. Los recintos habitacionales (de planta circular) sin acceso, están en el interior de corrales de distintas dimensiones y formas, divididos por calles principales y secundarias (delineadas por muros de doble hilera) presentes en Minas Pata, Mullaka Pata, y Raqa Raqay, Cóndor Rumi y Tarapampa. Las estructuras con fines defensivos (murallas y zanjas), se evidencian en los exteriores de los sitios, consisten en muros de doble hilera adosados de una zanja en la parte externa. Además, existe la presencia de abrigos rocosos y canteras cercanas a los sitios, donde se efectuaban los entierros (patrón de enterramiento característico del Intermedio Tardío). Por otro lado, las cimas más altas de los sitios estaban ligadas a la cosmovisión, como parte de las creencias del hombre prehispánico, las cuales se manifiestan de diferentes formas: materiales e inmateriales. La primera forma, mediante restos arquitectónicos, cuya finalidad es asignada a la ritualidad, tales como huancas (Cóndor Rumi), ushnu (Raqa Raqay) y recintos o patios circulares (Miski Ranra).

Los asentamientos prehispánicos en la frontera Este, Norte y Noroeste de la comunidad de Chaccchahua, distrito Huaccana, tuvieron una ocupación determinante hacia el medio que los rodeaban. Partiendo desde la ubicación, de manera estratégica, se sugiere que tuvieron un control territorial en más de una región. Es entonces, que la ubicación estratégica de cada poblado fue uno de los factores determinantes para el asentamiento de poblados en esta área, que también permitió el control territorial de una determinada área, incluyendo otras colindantes, en especial. Es así, que los sitios ubicados en la parte baja, estaban bajo en control territorial de los sitios Cóndor Rumi y Miski Ranra y los sitios de la parte alta por Raqa Raqay.

Las partes altas, parte superior de la región quechua, suni y puna (Pulgar, 1981), el sitio Raqa Raqay establecía un control territorial, tomando en cuenta su ubicación y organización, con una organización territorial, arquitectónica y de asentamiento bien constituida, dedicada a una actividad productiva como la agricultura y el pastoreo, por la presencia de extensas planicies en los alrededores y las abundantes gramíneas. Por otra parte, las partes bajas estaban controladas por dos sitios principalmente: Miski Ranra y Cóndor Rumi; dedicados a una variada actividad productiva agrícola, almacenaje y distribución, evidenciadas por la presencia de grandes extensiones de andenerías en los alrededores de los sitios, asociados a recintos habitacionales de planta circular y cuadrangular, que pudieron servir como almacenes.

El entorno medioambiental fue también un factor condicionante para el establecimiento de los poblados de esta época en esta parte de la región, situándose en tres regiones naturales, la región Yunga Fluvial (partes bajas como valles y quebradas), Quechua (partes medias) y Suni (partes altas con extensas planicies y cerros elevados), que les permitió el aprovechamiento, tanto de los recursos alimenticios propios de cada región, como también, la adquisición de materia prima de las canteras para la construcción de la arquitectura ubicados muy cerca de los asentamientos, y de los recursos hídricos como ojos de agua, manantiales, riachuelos que permitieron el normal desarrollo de la vida cotidiana.

Tomando en cuenta la propuesta de Murra (1975), creemos que el control territorial de los pisos ecológicos (regiones naturales) se dio de manera transversal recíproca, teniendo un núcleo de población a unos 3800 m.s.n.m. (región suni y puna) representado por el sitio de Raqa Raqay. Este sitio a la vez tenía como núcleos periféricos a sitios ubicados en los valles y quebradas, como Miski Ranra y Cóndor Rumi (región Yunga Fluvial). De los valles y quebradas como el Pampas y río Pulcay (fig. 43), posibilitó el aprovechamiento de los productos alimenticios propios de esta región como frutales, 
pescado, cabuya (para la elaboración de sogas), madera de diferentes tipos, y demás implementos e insumos provenientes de plantas silvestres (tintes y condimentos). Por otra parte, la región Quechua ofrecía una variedad de cereales (maíz en especial), leguminosas y las cucurbitáceas (zapallo, qawinca y calabaza), con el aprovechamiento al máximo de la frontera agrícola mediante la construcción de andenerías y terrazas agrícolas sobre los terrenos con más pendiente. Por último, la región Suni y Puna ofrecía una gran cantidad de tubérculos (papa, olluco, mashua, oca), quinua, plantas forrajeras como gramíneas (ichu y otros) propicios para la crianza de camélidos, carne deshidratada (charqui) y lana para la elaboración de vestimentas. Por otro lado; no se descarta el aprovechamiento de productos mediante el intercambio de la región ceja de selva, en la jurisdicción de la Oreja de Perro (Chungui), ya que hasta la actualidad se viene dando ese intercambio comercial. De ahí se proveía de productos como la coca, maní, cítricos, yuca, chonta, camote y plumas de aves.

Es así, que los recursos provenientes de los valles y quebradas eran almacenados en asentamientos afines para este fin, como los sitios de Miski Ranra, poblado grande con estructuras habitacionales de planta circular sin acceso rodeado de extensas áreas de andenerías y Cóndor Rumi, sitio caracterizado por la presencia de andenerías que vienen desde los 2800 m.s.n.m. hasta lo mas profundo del valle de Pulcay. De estos sitios fueron llevados a poblados núcleos de población situados en la parte más alta.

\section{CONCLUSIONES}

Los resultados de las investigaciones arqueológicas, en la frontera Este, Norte y Noroeste de la comunidad de Chaccchahua, distrito Huaccana, dan cuenta de una mayor ocupación durante el inter-

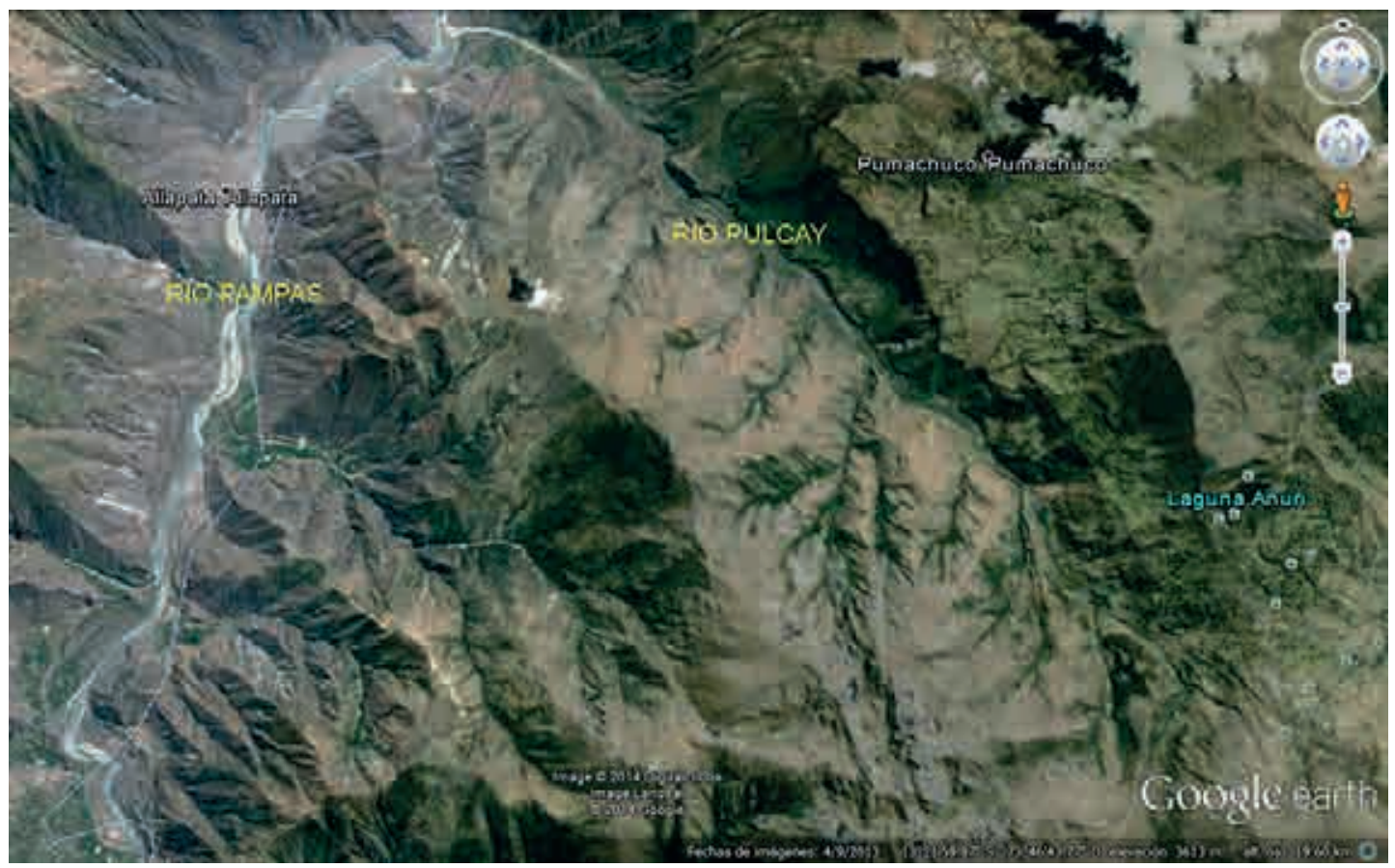

Fig. 42 vista satelital mostrando los dos valles, los cuales han sido aprovechados por los sitios ubicados en la frontera Este, Norte y Noroeste de la comunidad de Chaccchahua, distrito de Huaccana - Apurímac. 
medio tardío, por la mayor cantidad de evidencias encontradas. Estas evidencias acumuladas permitieron identificar los sitios como grupos étnicos, de carácter interdependiente, dentro de su ámbito de influencia, estos mismos, con un patrón arquitectónico complejo y muy bien organizado, que corresponden a poblados residenciales fortificados, compuestos de recintos habitacionales (de planta circular y cuadrangular), andenerías (divididos por muros) estructuras con fines defensivos (murallas y zanjas), funerarios (chullpas, cistas y abrigos rocosos), de almacenamiento (tambos y pequeños recintos circulares), ceremoniales (ushnus y plataformas en la cima de los cerros), y estructuras de circulación (calles principales y secundarios) (fig. 42), todos ellos asociados a material cultural, como cerámica y líticos.

Los resultados de las investigaciones arqueológicas, en la frontera Este, Norte y Noroeste de la comunidad de Chacchahua, distrito Huaccana, dan cuenta de una mayor ocupación durante el intermedio tardío, por la mayor cantidad de evidencias encontradas. Estas evidencias acumuladas permitieron identificar los sitios, con un patrón arquitectónico complejo y muy bien organizado, que corresponden a poblados residenciales fortificados, compuestos de recintos habitacionales (de planta circular y cuadrangular), andenerías (divididos por muros), estructuras con fines defensivos (murallas y zanjas), áreas funerarias (chullpas, cistas y abrigos rocosos), de almacenamiento (tambos y pequeños recintos circulares), ceremoniales (ushnus y plataformas en la cima de los cerros), y estructuras de circulación (calles principales y secundarias), todos ellos asociados a material cultural, como cerámica y líticos. Además, establecían un territorio de más de tres regiones naturales (Puna, Suni, Quechua y Yunga Fluvial), de manera tranversal recíproca, con intercambio de alimentos propios de cada zona. Para este control se estableció un núcleo poblacional ubicado a 3800 m.s.n.m. situado en la región suni y puna; y zonas periféricas en los valles y quebradas (partes más bajas). Estos núcleos de población servían como unidades de control y áreas de vivienda, en cambio las zonas periféricas como área de abastecimiento y almacenaje, teniendo en cuenta las evidencias, como la presencia de unidades residenciales de planta circular sin acceso y áreas extensas de andenerías.

\section{Agradecimientos}

El autor de este artículo desea expresar su más profundo agradecimiento a todos aquellos que directa o indirectamente apoyaron la elaboración del presente trabajo. Primeramente a mis padres por su apoyo incondicional. A mis amigos Henry Navarro, Ayme Cáceres, Ciro Cure, Anays Amorín y en especial a Auria Carina Paullo, quienes nos acompañaron e hicieron posible la realización de los trabajos de campo y gabinete. Por último, en especial consideración a los pobladores de la comunidad de Chaccchahua, presididos por el Sr. Virgilio Pérez Nauto, quienes nos permitieron la realización del trabajo de investigación.

\section{Bibliografía}

\section{AÑANCA ANCHAYHUA, William y Miguel CANCHARI HUAMÁN}

2009 "Prospección Arqueológica en la Micro-Cuenca del Rio Churruwayqu, Chungui-La Mar". Informe de prácticas pre-profesionales, E.F.P. de Arqueología e Historia, Universidad Nacional de San Cristóbal de Huamanga. Ayacucho - Perú.

2010 "Investigaciones Arqueológicas en la micro cuenca del rio Churruwayqu, Chungui - La Mar”. Revista Pacha Runa, N 1, 2010: 219 - 252. Edison Mendoza M. (editor). Universidad Nacional de San Cristóbal de Huamanga, gobierno regional de Ayacucho, instituto de investigaciones históricas, arqueológicas y antropológicas (IDHAPAR). 
AÑANCA ANCHAYHUA, William

2013 "El Intermedio Tardío en el VRAE: Investigaciones Arqueológicas en Llaqta Pata, Chungui - La Mar”. Informe de tesis, E.F.P. de Arqueología e Historia, Universidad Nacional de San Cristóbal de Huamanga. Ayacucho - Perú.

BAUER, Brian; Miriam ARAOZ y Lucas KELLETT

2004 "Informe Preliminar del Proyecto Arqueológico Andahuaylas". Informe presentado al Instituto Nacional de Cultura.

BAUER, Brian y Miriam ARÁOZ

2010a “La fase Qasawirka en la región de Andahuaylas (Apurímac, Perú)”. Arqueología en el Perú Nuevos aportes para el estudio de las sociedades andinas prehispánicas, pp.: 151-173. Editores Rubén Romero Velarde y Trine Pavel Svendsen. Universidad Nacional Federico Villarreal. Lima.

BAUER, Brian; Lucas, KELLETT y Miriam ARAÓZ SILVA

2010 b “The Chanka: Archaeological Research in Andahuaylas (Apurímac), Peru”. Series Monograph 68.

BAUER, Brian. y Lucas KELLET

2010c "Cultural transformations of the Chanka homeland (Andahuyaylas, Per) during the Late Intermediate Period (A.D. 1000-1400)". Latin American Antiquity 21(1), p. 87-111.

DÉODAT, Laure; Patrice, LECOQ y Cirilo VIVANCO POMACANCHARI

2010 “Prospección Arqueológica en Chungui, La Mar, Ayacucho: Aspecto Metodológico”. Investigación, vol. 18, N² 2, pp. 130-142. Oficina General de Investigación e Innovación, Universidad Nacional de San Cristobal de Huamanga, Ayacucho.

ESPINOZA GONZÁLEZ, Rubén

2003 "Prospección Arqueológica en la Margen Derecha del Rio Pampas, Distrito Huaccana - Provincia Chincheros”. Informe de práctica pre-profesional. E.F.P. de Arqueología e Historia, Universidad Nacional de San Cristóbal de Huamanga. Ayacucho.

GÓMEZ CHOQUE, Diógenes. E.

2009 Investigación en sitios de inhumación en Andahuaylas: una aproximación Bioarqueológica y arqueomortoria. Tesis para optar el título profesional. Licenciado en arqueología. E.F.P. de Arqueología e Historia, Universidad Nacional de San Cristobal de Huamanga. Ayacucho.

GONZALES Carré, Enrique; POZZI-SCOT, Denise y Cirilo VIVANCO POMACANCHARI

1988 Área Histórica Chanka. Laboratorio de Arqueología, E.F.P. de Arqueología e Historia, Universidad Nacional de San Cristobal de Huamanga. Ayacucho.

LITVAK KING, Jaime

2000 Introducción a la Arqueología: Todas las Piedras Tienen 2000 Años. 2a ed., Edit. Trillas. México.

LUMBRERAS SALCEDO, Luis Guillermo

1974 La Arqueología Como Ciencia Social. Ediciones Histar. 1a ed. (Serie de arqueología 1). Lima Perú. 
MORALES AGUILAR, Carlos Arturo

2010 Patrones de Asentamiento en el Área Central de El Mirador, Peten, Guatemala, durante el Periodo Clásico Tardío (600 - 850 d.C.). Tesis de licenciatura en Arqueología, Escuela de Historia, Universidad de San Carlos de Guatemala, nueva Guatemala de la Asunción.

MURRA, John V.

1975 Formaciones Económicas y Políticas del Mundo Andino. Instituto de Estudios peruanos (IEP). Historia Andina 3. 1a ed. Lima - Perú.

PÉREZ, Ismael; VIVANCO, Cirilo y José AMORIN

2003 “Sondor, establecimiento inca en Pacucha, Andahuaylas". Boletín de Arqueología PUCP, № 7, pp. 265-286. Fondo Editorial del PUCP, Lima.

QUISPE Curi, Socorro

2001 Visión del Patrimonio Turístico de la Provincia de Andahuaylas. Trabajo Monográfico para Optar Titulo de Licenciatura en Arqueología e Historia. Facultad de Ciencias Sociales. Universidad Nacional San Cristobal de Huamanga. Ayacucho-Perú.

RENFREW, Colin y Paul BAHN

1998 Arqueología: Teorías, Métodos y Práctica. Editorial AKAL. 2a ed. Madrid - España.

RAVINES SÁNCHEZ, Rogger Hernán

1989 Arqueología Práctica. Editorial Los Pinos E.I.R.L. 1a ed. Lima - Perú.

SALCEDO OLARTE, William

2009 "Sitios arqueológicos de la microcuenca alta del Rio Chincheros Anco-Huallo, Uripa-Apurímac". Informe practicas pre-profesionales, E.F.P. de Arqueología e Historia, Universidad Nacional de San Cristobal de Huamanga. Ayacucho.

VALER Palomino, Salvador

2006 Reconocimiento Arqueológico en la Margen Derecha del Rio Pampas, Comunidades de Maramara, Huaccana y Pumachuco Distrito de Huaccana, Provincia de Chincheros-Apurímac. Informe de práctica pre-profesional. E.F.P. de Arqueología e Historia, universidad nacional de san Cristóbal de Huamanga. Ayacucho.

VIVANCO Pomacanchari, Cirilo

2011a Investigaciones Arqueológicas en Huaccana y Ongoy, Chincheros - Apurímac. Informe final. Instituto de Investigación de la Facultad de Ciencias Sociales. Programa: Ciencias Históricos Sociales, Área: Arqueología. Universidad Nacional de San Cristóbal de Huamanga. Ayacucho.

2011b Investigaciones Arqueológicas en Huaccana y Ongoy, Chincheros - Apurímac. Entidades Políticas Locales y la Presencia Inka en el Valle Bajo del Pampas. Instituto de Investigación de la Facultad de Ciencias Sociales. Programa de Investigación Ciencias Históricos Sociales. Área Arqueología. Universidad Nacional de San Cristóbal de Huamanga. Ayacucho.

2011c “Sitios Wari en Chungui - La Mar: Área de Contacto entre la Selva y Sierra". Revista Conchopata $\mathrm{N}^{\circ}$ 3: 235-258. E.F.P. de Arqueología e Historia, Universidad Nacional de San Cristóbal de Huamanga. Ayacucho. 
